Published in final edited form as:

Neuroscience. 2016 December 3; 338: 114-129. doi:10.1016/j.neuroscience.2016.06.006.

\title{
Neurobiology of fibromyalgia and chronic widespread pain
}

\author{
Kathleen A. Sluka, PT, PhD, FAPTA and \\ Professor of Physical Therapy and Rehabilitation Science, Pain Research Program, University of \\ lowa \\ Daniel J. Clauw, MD \\ Professor of Anesthesiology, Medicine (Rheumatology) and Psychiatry, University of Michigan
}

\section{Introduction}

Clinical practitioners commonly see patients with pain and other somatic symptoms that they cannot adequately explain based on the degree of damage or inflammation noted in peripheral tissues (Kroenke and Mangelsdorff, 1989). If no cause is found, these individuals are often given a diagnostic label that merely connotes that the patient has pain in a region of the body such as chronic low back pain, headache, or temporomandibular joint disorder. In other cases, the label given alludes to an underlying pathologic abnormality that may or may not be responsible for the individual's pain, such as endometriosis and facet syndrome. In the worst case scenario, these patients are told that there is nothing wrong with them, advised that the disorder is "all in their head," and given a label such as "somatizer" without being offered any treatment.

Fibromyalgia (FM) is the current term for chronic widespread musculoskeletal pain for which no alternative cause can be identified. Depending on the practitioner a patient sees, there are a number of related and overlapping conditions, which have recently been referred to as chronic overlapping pain conditions or functional pain disorders. For example, gastroenterologists often see the very same patients using the terms functional gastrointestinal disorder, irritable bowel syndrome (IBS), nonulcer dyspepsia, or esophageal dysmotility to explain the patients' symptoms, while urologists see these patients for pelvic pain and urinary symptoms using the terms interstitial cystitis, chronic prostatitis, vulvodynia, and vulvar vestibulitis, and dentists see patients for temporomandibular joint syndrome. These chronic overlapping pain conditions are thought to have similar underlying pathology with alterations in central nervous system function leading to augmented nociceptive processing and the development of central nervous system (CNS)-mediated somatic symptoms of fatigue, sleep, memory and mood difficulties. There is a different subset of individuals with fibromyalgia who have this condition as a co-morbidity with another disorder known to cause ongoing nociceptive input, such as autoimmune disorders,

Corresponding Author: Kathleen A. Sluka, PT, PhD, FAPTA, University of Iowa Department of Physical Therapy \& Rehabilitation Science, 500 Newton Road, 1-252 MEB, Iowa City, IA 52242, Phone: 319-335-9791, Fax: 319-335-9707, kathleen-sluka@uiowa.edu. Publisher's Disclaimer: This is a PDF file of an unedited manuscript that has been accepted for publication. As a service to our customers we are providing this early version of the manuscript. The manuscript will undergo copyediting, typesetting, and review of the resulting proof before it is published in its final citable form. Please note that during the production process errors may be discovered which could affect the content, and all legal disclaimers that apply to the journal pertain. 
sickle cell disease, or osteoarthritis (Clauw, 2014). This subset of fibromyalgia, formerly termed secondary fibromyalgia appears similar phenotypically and mechanistically, but may also have a strong nociceptive input driving the central sensitization since the CNS changes appear to improve when peripheral nociceptive input is removed (Kosek and Ordeberg, 2000, Gwilym et al., 2010, Gwilym et al., 2011).

The underlying mechanisms for the continued pain in individuals with fibromyalgia will be explored in this review. There is a substantial amount of support for alterations of central nervous system nociceptive processing in people with fibromyalgia, and that psychological factors such as stress can enhance the pain experience. At present we feel that the central nervous system mechanisms show the strongest evidence of true pathogenesis - in that they share common pathogenic features in both human and animal models, and respond to treatments aimed at those particular mechanisms. However, more recently a number of studies have begun exploring other potential mechanisms including a peripheral component to the generation of pain and the role of systemic inflammation. We will explore the data and neurobiology related to the role of the CNS in nociceptive processing, followed by a short review of studies examining potential peripheral nervous system changes and cytokine involvement. We will not only explore the data from human subjects with fibromyalgia but will relate this to findings from animal models of fibromyalgia.

\section{Overview of central nervous system alterations in fibromyalgia}

\section{Human animals}

Individuals with fibromyalgia present with diffuse hyperalgesia (increased pain to normally painful stimuli) and/or allodynia (pain to normally nonpainful stimuli). The widespread nature of the pain is a key clinical feature in these individuals and a number of other CNSmediated symptoms, i.e. fatigue, memory difficulties, sleep and mood disorders, are frequent comorbidities. Together, this supports that the CNS was amplifying pain, and there is a fundamental problem with augmented pain or sensory processing in the CNS. These findings of augmented pain and sensory processing are corroborated by the presence of these same phenomena in functional neuroimaging studies, and imbalances in levels of neurotransmitters that affect pain and sensory transmission in individuals with fibromyalgia (Schmidt-Wilcke and Clauw, 2011, Harris and Clauw, 2012, Clauw, 2014). Further similar types of therapies are efficacious for all of these conditions, including both pharmacologic treatments aimed at increasing antinociceptive neurotransmitters in the central nervous system, or those that lower levels of pronociceptive excitatory neurotransmitters such as glutamate. A number of non-pharmacologic treatments, such as exercise, can also be extremely helpful and alter endogenous neurotransmission including increasing antinociceptive neurotransmitters and reducing glutamate (Sluka et al., 2013, Bobinski et al., 2015). Conversely, individuals with these conditions typically do not respond well when given therapies that are effective for acute pain or pain caused by damage to or inflammation of tissues such as, nonsteroidal antiinflammatory drugs [NSAIDs], local injections, or surgical procedures.

Animal models have been developed to mimic and gain a better understanding of the neurobiology of chronic widespread pain. The most common and well characterized models 
involve repeated insults to the muscle. A non-inflammatory pain model is induced by repeated injections of acid saline $(\mathrm{pH}$ 4.0) into the same gastrocnemius muscle and produces widespread hyperalgesia of the skin, muscle and viscera without observable tissue damage or inflammation (Sluka et al., 2001, Miranda et al., 2004, Yokoyama et al., 2007b, Sharma et al., 2009). In addition this model is associated with anxiety-like and depression-like behaviors in a 50-60\% of animals after induction of the model (Liu et al., 2014). A modification of the non-inflammatory model combines muscle fatigue with repeated acid injections ( $\mathrm{pH}$ 5.0) and similarly produces widespread and long-lasting hyperalgesia without observable tissue damage or inflammation (Yokoyama et al., 2007b, Sluka and Rasmussen, 2010, Gregory et al., 2013). In the fatigue-induced pain models female mice have greater, more widespread, and longer lasting hyperalgesia when compared to male mice (Sluka and Rasmussen, 2010, Gregory et al., 2013).

Underlying mechanisms in the non-inflammatory model appear to be centrally mediated since removal of afferent input from the injected site has no effect on the contralateral hypersensitivity in the repeated acid injection model (Sluka et al., 2001). while the hypersensitivity once developed is reversed by blockade of excitatory activity spinally or supraspinally (Skyba et al., 2002, Hoeger-Bement and Sluka, 2003, Tillu et al., 2008, da Silva et al., 2010a, da Silva et al., 2010b). Further the non-inflammatory pain model shows a similar pharmacological management profile to clinical treatment of fibromyalgia: reductions in pain and hyperalgesia by antidepressants, anticonvulsants, opioids, glutamate receptor antagonists, $\mathrm{K}^{+}$channel openers, $\mathrm{Na}+$ channel blocker and exercise, but not NSAIDS (Sluka et al., 2002, Nielsen et al., 2004, Bement and Sluka, 2005, Miranda et al., 2006, Yokoyama et al., 2007a, Kim et al., 2009, Sharma et al., 2010). Thus, the noninflammatory pain models mimic the clinical presentation of signs and symptoms observed in fibromyalgia with widespread hyperalgesia, minimal muscle tissue damage, alterations in central nociceptive processing, greater hyperalgesia in females, and are responsive to the same pharmacological and non-pharmacological therapies.

\section{Augmented pain and sensory processing}

Although clinical descriptions of individuals with symptoms consistent with fibromyalgia have been present for millennia, the first widely recognized diagnostic criteria for fibromyalgia were published in 1990 (Wolfe et al., 1990). The diagnostic criteria requires individuals present with chronic widespread pain and at least 11 out of 18 positive tender points located throughout the body (Wolfe et al., 1990). Early investigators established the tenderness in fibromyalgia was not confined to tender points, but in fact was diffusely present (Smythe, 1986, Gerecz-Simon et al., 1989, Lautenbacher et al., 1994, Kosek et al., 1995). At the same time, skeletal muscle was largely abandoned as a source of the pain since imaging, biopsy, and metabolic studies of muscle were generally unremarkable (Simms et al., 1994, Wortmann, 1994, Vestergaard-Poulsen et al., 1995). It was also well understood that other non-pain symptoms such as fatigue, sleep and mood problems were extremely common in fibromyalgia, and were much more likely to all be caused by central rather than peripheral factors (Yunus et al., 1981, Yunus et al., 1982, Wolfe et al., 1990, Wolfe et al., 1995). Alterations in the hypothalamic pituitary adrenal (HPA) axis and stress response (see details below), as well as the autonomic and cardiovascular system, suggest systemic effects 
that may enhance or underlie the pain of fibromyalgia (Crofford, 1996, Clauw and Chrousos, 1997, Pillemer et al., 1997, Petzke and Clauw, 2000). Thus, there is significant clinical data that suggests central nervous system alterations in individuals with fibromyalgia. However, more recent studies, outlined below, using more sophisticated analyses of peripheral factors have begun to see some differences that might contribute to peripheral pathology (Shang et al., 2012, Srikuea et al., 2013, Uceyler et al., 2013).

Since diffuse tenderness was a defining feature of fibromyalgia more sophisticated quantitative sensory testing (QST) methods were subsequently used to determine whether the diffuse tenderness could be due primarily to either psychological factors or neurobiologic factors. These studies showed the following: (1) fibromyalgia patients are more sensitive to pressure anywhere in their body - tender points merely represent regions where everyone is more tender (Kosek et al., 1995, Wolfe, 1997, Petzke et al., 1999a, Graven-Nielsen et al., 2000), (2) randomly applied pressure pain threshold are not influenced by levels of distress of the individual, whereas tender point count is (Petzke et al., 1999b, Petzke et al., 2003a, Petzke et al., 2003b), (3) fibromyalgia patients were not any more expectant or hypervigilant than controls, (4) Pressure pain thresholds at any four points in the body are highly correlated with the average tenderness at all 18 tender points and control points (Petzke et al., 2001), (5) fibromyalgia patients also display a decreased threshold to other noxious stimuli, heat, cold, and electrical stimuli (Kosek and Hansson, 1997, Sorensen et al., 1998, Carli et al., 2002, Desmeules et al., 2003, Petzke et al., 2003a), and (6) fibromyalgia patients are more sensitive to other sensory stimuli such as sound (Gerster and Hadj-Djilani, 1984, Dohrenbusch et al., 1997, Geisser et al., 2008). Thus, fibromyalgia and related syndromes might represent biologic amplification of all sensory stimuli gains, and terms such as sensory sensitivity syndrome have been suggested as a unifying pathophysiological theme (Yunus, 2015).

Imaging studies confirmed altered central neural processing in nociceptive pathways. Using fMRI, a noninvasive brain imaging technique that assesses changes in relative concentration of oxygenated to deoxygenated hemoglobin, neuronal activation associated with a noxious stimulus is subtracted from neuronal activation seen during a control condition (often light touch). Gracely and coworkers (Gracely et al., 2002), initially used fMRI to show that fibromyalgia patients had greater amounts of neuronal activation in pain-processing regions of the brain than control subjects when they were given the same amount of pressure stimuli (see Figure 1). These findings, confirmed in later studies, are consistent with a left shift in stimulus-response function noted with experimental pain testing suggesting that most fibromyalgia patients have an increased gain or "volume setting" in brain pain-processing systems (Coghill et al., 2003, Giesecke et al., 2004, Gracely et al., 2004). In fMRI studies, the brain regions that most strongly encode for stimulus intensity are the posterior insula and the secondary somatosensory cortices, and these are the brain regions where neuronal activation will be most accentuated in individuals with diffuse hyperalgesia or allodynia (Wager et al., 2013, Segerdahl et al., 2015). One of the main reasons for subtle differences in fMRI findings in fibromyalgia or other chronic pain studies is because differing stimuli of differing intensity are used in the scanning session. Results would be different if the same stimuli are used for each participant or normalized to induce a certain level of pain. Lastly, varying degrees of co-morbidities that can also influence imaging results. 
fMRI has also proved useful in determining how comorbid psychological factors influence pain processing in fibromyalgia. For example, Giesecke and colleagues found that anterior insula and amygdala activation were correlated with depressive symptoms, consistent with these medial and prefrontal brain regions' being involved in affective or motivational aspects of pain processing. In contrast, the degree of neuronal activation in more lateral structures, thought to be involved in the sensory processing of pain were not associated with levels of depressive symptoms or the presence or absence of major depression (Giesecke et al., 2005). These data are consistent with a plethora of evidence in the pain field indicating that there are different regions of the brain responsible for pain processing devoted to sensory intensity and to affective aspects of pain sensation, and suggest that the former and latter are largely independent of each other (Gracely et al., 2004, Lee and Tracey, 2013, Tracey, 2013, Eippert and Tracey, 2014, Segerdahl et al., 2015).

A more recent advance is the use of fMRI to look at the extent to which brain regions are connected to each other. This analysis can be applied to fMRI data acquired either when individuals are resting, termed resting state analysis, or when they are performing a task. The advantage of resting state analysis is that it does not require giving the participant a stimulus, and thus it potentially provides a window into measurement of brain changes associated with chronic, ongoing spontaneous pain. Napadow and Harris have used this technique to demonstrate that individuals with FIBROMYALGIA show increased connectivity between the default mode network, a network active when the brain is resting and not performing any specific task, and the insula, a known pronociceptive region of the brain (Napadow et al., 2012, Segerdahl et al., 2015). Furthermore, in these studies the degree of increased connectivity was related the intensity of ongoing, spontaneous pain (Napadow et al., 2010). Several other groups have shown a strong relationship between ongoing spontaneous pain, and hyperconnectivity between the insula and the default mode network in other chronic pain conditions (Letzen et al., 2013, Loggia et al., 2013). Other brain regions may be hypo-connected in fibromyalgia and other centralized pain states. For example, during a painful stimulus connectivity is decreased between key antinociceptive regions in the brainstem in individuals with fibromyalgia, suggesting a defect in the normal descending inhibitory systems in this condition, as suggested by findings of decreased conditioned pain modulation on quantitative sensory testing (Jensen et al., 2012).

In summary, there is enhanced processing in areas in involved in the sensory and affective processing of pain, increases in resting state connections with the insula which is involved in processing nociceptive stimuli, and decreases in connectivity in antinociceptive regions in people with fibromyalgia. As you will see below, these altered processing in central sites are mimicked in animal models, and are associated with changes in neurotransmitters and receptors in both humans and animal models of fibromyalgia.

\section{Evidence for enhanced excitation in the central nervous system}

\section{Human Studies}

A number of studies have examined for enhanced central nervous system activity using temporal summation, manifested as an increase in pain to a repeated stimulation to the same noxious stimuli, which is thought to be the human-analog of the neuronal phenomenon, 
"wind up," observed in animals (Dickenson and Sullivan, 1987). These findings of temporal summation have been noted in some fibromyalgia studies but not all (Price et al., 2002, Staud et al., 2003, Staud et al., 2008, Potvin et al., 2012).

There is more consistent evidence that excitatory CNS neurotransmitters, involved in enhancing wind-up and central sensitization, are elevated in fibromyalgia and could play a pathogenic role. Four independent studies show that patients with fibromyalgia have approximately threefold higher concentrations of substance $\mathrm{P}$ in the CSF compared with normal controls (Russell et al., 1996, Russell, 1998, Schwarz et al., 1999). However, SP antagonists have failed in clinical trials in chronic pain states, casting questions about how critical this neurotransmitter is in human pain transmission. In addition to substance $\mathrm{P}$, elevations in CNS glutamate levels in fibromyalgia, measured both in the CSF (Sarchielli et al., 2007) and directly in the brain using proton spectroscopy (H-MRS) are also found in individuals with fibromyalgia (Harris et al., 2009, Fayed et al., 2010, Harris, 2010). In fact, using proton magnetic resonance spectroscopy, glutamate levels in fibromyalgia patients are also elevated in key pain-processing areas of the brain such as the insula and change in response to changes in both clinical and experimental pain when patients are successfully treated (Harris et al., 2008, Harte et al., 2013, Foerster et al., 2015). For example, pregabalin decreases glutamatergic activity in the insula and decreases functional connectivity between the default mode network and insula in individuals with fibromyalgia (Harris et al., 2013). In this study individuals with the highest levels of glutamate in the insula before treatment were the ones most likely to respond to pregabalin, and functional neuroimaging parameters purported to be pathogenic in fibromyalgia, e.g. increased connectivity between insula and default mode network, improved in those individuals deriving benefit from pregabalin. There is also strong evidence that subsets of fibromyalgia patients respond to drugs known to be $\mathrm{N}$ methyl-D-aspartate (NMDA) glutamate receptor antagonists, which suggests that glutamatergic activity is increased; unfortunately, these drugs, such as ketamine or dextromethorphan, or memantine, are often not well tolerated and thus not always practical for clinical use (Graven-Nielsen et al., 2000, Staud et al., 2005, Cohen et al., 2006, OlivanBlazquez et al., 2014). As an alternative, a low glutamate diet has also been demonstrated to reduce symptoms in people with fibromyalgia (Holton et al., 2012).

Finally, these same excitatory CNS neurotransmitters are also thought to play critical pathogenic roles in other co-morbid symptoms seen commonly in fibromyalgia. For example, when an individual with fibromyalgia responds favorably to a gabapentinoid drug, they typically note improvements in many other symptom domains such as sleep, anxiety, and fatigue, suggesting that in other brain regions these same neurotransmitter imbalances lead to these co-morbid symptoms (Baidya et al., 2011).

\section{Animal Studies}

Central excitatory mechanisms involving the spinal cord, brainstem and cortex have also been implicated in the development of hyperalgesia in animal models of non-inflammatory muscle pain induced by two injections of acidic saline. In parallel to the human studies, animal studies show enhanced release of glutamate in the spinal cord and rostral ventromedial medulla (RVM) in the non-inflammatory pain model (Skyba et al., 2005, 
Radhakrishnan and Sluka, 2009) (Figure 2). These studies show enhanced glutamate release during the second acidic saline injection, but not the first injection, in both the spinal cord and the RVM. There are also increased glutamate levels in the spinal cord after induction of the model (Skyba et al., 2005). The increased glutamate in response to the second injection corresponds to the development of long-lasting widespread hyperalgesia that occurs only after the second injection. These data suggest there is increased excitability in the central nervous system induced by a single low-intensity muscle insult that sets up the nervous system to respond to the same stimulus in an exaggerated way to a subsequent stimulus.

Like people with fibromyalgia, the animal models are responsive to blockade of NMDA receptors. Development of hyperalgesia is delayed by blockade of NMDA-glutamate receptors in the spinal cord during the second injection but not the first (Skyba et al., 2002), and reversed by blockade of NMDA glutamate receptors in the spinal cord and RVM after induction of the model (Skyba et al., 2002, da Silva et al., 2010a, da Silva et al., 2010b) (Figure 2). The NR1 subunit of the NMDA receptor plays a critical role in neuron excitability and is required for formation of the receptor as well as insertion into the synapse. In the spinal cord, there is enhanced NR1 expression in spinothalamic tract cells after induction of the non-inflammatory pain model (Bement and Sluka, 2007). Overexpression of the NR1 subunit of the NMDA receptor in the RVM, using an FIV-expressing the cDNA to NR1, produces widespread hyperalgesia similar to that observed in the noninflammatory pain model. On the other hand, downregulation of NR1 in the RVM, using FIV-expressing an miRNA to NR1, prevents development of hyperalgesia in the noninflammatory pain model (Figure 2). Phosphorylation of the NR1 subunit can enhance the responsiveness of the NMDA receptor making it more responsive to glutamate and more likely to enter the synapse. In the non-inflammatory pain model, there is enhanced phosphorylation of NR1 in the RVM that is modulated by effective treatment (da Silva et al., 2010a, da Silva et al., 2010b)(Figure 2). Together these data show a role of NMDA glutamate receptors in the central nervous system in initiating and maintaining widespread hyperalgesia.

Changes in intracellular messengers can produce long-lasting effects by altering excitability of neurons and enhancing gene transcription. Spinally, there are increases in the transcription factor CREB (cAMP-responsive element binding protein) and in phosphorylation of CREB 24h after induction of the non-inflammatory pain model (HoegerBement and Sluka, 2003). Blockade of the cAMP-intracellular messenger pathway reverses the hyperalgesia in the non-inflammatory pain model, showing the functional role of intracellular messengers in maintaining pain-like behaviors. Further, the intracellular signaling molecule ERK is phosphorylated in paraventricular thalamus and the central nucleus of the amygdala in the non-inflammatory pain model (Chen et al., 2010b). The brainstem sites may drive some of the cortical changes since there is enhanced postsynaptic excitatory transmission from the parabrachial nucleus to the central nucleus of the amygdala (Cheng et al., 2011). The hyperalgesia and the increases in phosphorylation of ERK in the amygdala are prevented by intracerebroventricular blockade of T-type Ca2+ channels ( $\mathrm{T}$ channels)(Chen et al., 2010a) suggesting calcium channels may mediate some of these changes. Thus, animal studies show alterations in central excitability throughout the nociceptive system from spinal cord to cortex in chronic widespread pain models. 


\section{Alterations in central inhibition also contribute to underlying pathology in fibromyalgia}

\section{Animal and human studies}

The central nervous system balances the amount of excitation and inhibition. Normally there is an equal balance to the amount of excitability and inhibition and there is no pain. In people with chronic pain this balance shifts so that there is enhanced excitation and reduced inhibition resulting in pain. In healthy humans and laboratory animals, application of an intense painful stimulus produces generalized whole-body analgesia. This analgesic effect, originally termed diffuse noxious inhibitory control(DNIC) and more recently conditioned pain modulation (CPM), is consistently reduced or even absent in groups of people with fibromyalgia compared with healthy controls (Kosek and Hansson, 1997, Julien et al., 2005). This phenomenon is also observed in a number of other chronic functional pain states, including low back pain, TMJ, IBS, and headache (Mayer and Gebhart, 1994, Kosek and Hansson, 1997, Lautenbacher and Rollman, 1997, Julien et al., 2005, Wilder-Smith and Robert-Yap, 2007, Yarnitsky, 2010). Attenuated CPM is not found in all patients with fibromyalgia or chronic pain but is considerably more common in these patients than in control subjects. DNIC (CPM terminology for animals) activates a unique site in the brainstem, the subnucleus reticularis dorsalis, but does not involve other more well-known pain inhibitory sites such as the PAG and RVM (De Resende et al., 2011). In animals pharmacologically DNIC uses opioidergic, serotonergic and noradrenergic receptors to produce analgesia (Yaksh, 1985, Le Bars and Villanueva, 1988, Roerig et al., 1988, Le Bars et al., 1992).

In fibromyalgia, the available evidence suggests that endogenous opioid tone is normal or even increased in fibromyalgia. Individuals with fibromyalgia and chronic low back pain have higher levels of CSF enkephalins than controls (Baraniuk et al., 2004), and in a PET study showed that of fibromyalgia patients who had never received an exogenous opioid had reduced baseline $\mu$-opioid receptor binding in multiple pain-processing regions in the brain (Harris et al., 2007). In recent studies, individuals with chronic pain conditions such as osteoarthritis or chronic pelvic pain, that have higher fibromyalgia scores on the 2011 fibromyalgia Survey Criteria, which does not require performing a tender point count, have markedly increased opioid consumption in the immediate perioperative period (Brummett et al., 2013, Janda et al., 2015). There is even emerging evidence that blocking endogenous opioid release with the use of low-dose naltrexone might be an effective treatment strategy in some fibromyalgia patients (Younger and Mackey, 2009). Together these data are consistent with the hypothesis that there is increased release of endogenous $\mu$-opioid ligands in fibromyalgia leading to high baseline occupancy of the receptors, rather than a deficiency of endogenous opioid release, which would be expected if the decreased CPM has due to low endogenous opioid tone.

In contrast, there is significant evidence that the reduced CPM in fibromyalgia may result from decreased endogenous serotonergic and noradrenergic activity. The levels of the principal metabolite of norepinephrine, 3-methoxy-4-hydroxyphenethylene, are lower in the cerebrospinal fluid (CSF) of fibromyalgia patients. Similarly, patients with fibromyalgia 
have reduced serum levels of serotonin and its precursor, tryptophan, as well as reduced levels of the principal serotonin metabolite, 5-HIAA, in their CSF (Russell et al., 1992). In parallel, animal studies show, in the brainstem, reduced serotonin release, enhanced expression of the serotonin transporter, and alterations in serotonin receptors after peripheral nerve injury (Bobinski et al., 2015), and enhanced expression of the serotonin transporter in the brainstem in the non-inflammatory muscle pain model (Sluka, unpublished observations). Further, depletion of biogenic amines in rats, by reserpine, produces longlasting widespread muscle and cutaneous hyperalgesia in both male and female rats. There is also an increase in immobility time in the forced swim test, a test for depression which a common comorbid symptom of fibromyalgia (Nagakura et al., 2009).

The best evidence that low levels of these neurotransmitters is involved in the pathogenesis of fibromyalgia comes from clinical trials in which nearly any intervention that simultaneously raises both serotonin and norepinephrine levels (serotonin-norepinephrine reuptake inhibitors [SNRIs] such as tricyclics, duloxetine, milnacipran, tramadol) is efficacious in treating fibromyalgia and related conditions (Clauw, 2014). QST studies have shown that individuals with neuropathic pain with the lowest CPM at baseline were most likely to respond to duloxetine (Yarnitsky et al., 2012), whereas neuroimaging studies showed that fibromyalgia patients with the least baseline connectivity to the PAG were most likely to respond to milnacipran (Schmidt-Wilcke et al., 2014). In fact, many analgesic treatments are likely working in part by restoring descending analgesic activity. Similarly, individuals with fibromyalgia show enhanced pain relief with transcutaneous electrical nerve stimulation (TENS), which activates central inhibitory pathways, and simultaneously show restoration of CPM (Dailey et al., 2013). Both sleep and exercise likely work in part via restoring analgesic activity (Sluka et al., 2013, Bobinski et al., 2015). In fact, in animals with neuropathic pain, exercise-induced analgesia is prevented by depletion of serotonin, and exercise increases serotonin levels, reduces the serotonin transporter expression, and increases serotonin receptor expression in the brainstem (Bobinski et al., 2015). Thus, nonpharmacological treatments alter central nervous system function by enhancing central inhibition pathways that are altered in chronic widespread pain.

\section{Stress and psychological factors are involved in the development and severity of fibromyalgia}

\section{Human Studies}

Disparate stressors can trigger the development and severity of functional pain conditions such as fibromyalgia. In fact, both human and animal studies have been examined to determine if stress has a causative role in the development of chronic pain. In humans, daily hassles and personally relevant stressors seem to be more capable of causing symptoms than major catastrophic events that do not personally impact the individual. Two studies performed in the United States just before and after the terrorist attacks of 9/11 illustrate this latter point. In one study, no difference in pain complaints or other somatic symptoms was seen in residents of New York and New Jersey who were surveyed before 9/11 and then surveyed just following the terrorist attacks on the World Trade Center (Raphael et al., 2002). In another study performed in the Washington, DC, region near the Pentagon(another 
site of attack) during the same time period, patients with fibromyalgia had no worsening of pain or other somatic symptoms following the attack, compared to just before the attack (Williams et al., 2003). On the other hand, changes in baseline function of the stress response, mainly the autonomic and neuroendocrine systems, may occur following a stressor earlier in life. Early life stressors can predict which symptom-free individuals without chronic pain are more likely to develop chronic pain. This has been noted both in population-based studies and in experiments in which healthy young adults are deprived of regular sleep or exercise (Glass et al., 2004, Ablin et al., 2013). In fact, people fibromyalgia and related conditions may be more likely than non-affected individuals to have experienced physical or sexual abuse in childhood (McBeth et al., 2001).

Because of this link between exposure to stressors and the subsequent development of fibromyalgia, the human stress systems have been extensively studied in this condition. These studies generally show alterations of the hypothalamic-pituitary-adrenal (HPA) axis and the sympathetic nervous system in fibromyalgia and related conditions (Martinez-Lavin and Hermosillo, 2000, Crofford, 2002). Although these studies often note either hypoactivity or hyperactivity of both the HPA axis and sympathetic nervous system in individuals with fibromyalgia and related conditions, the precise abnormality varies from study to study. Moreover, these studies find abnormal HPA or autonomic function in only a very small percentage of patients, and there is tremendous overlap between patients and control subjects. The inconsistency of these findings should not be surprising, since nearly all of these studies were cross-sectional studies which assumed that if HPA and/or autonomic dysfunction was found in fibromyalgia, it must have caused the pain and other symptoms. Data now suggest a much more complicated picture, and suggest that HPA and autonomic abnormalities might represent be due to the pain (McLean et al., 2006). Emerging data suggest that the picture is a very complicated one, with good evidence for a role of "sympathetic overdrive" (especially at night) in a subset of fibromyalgia patients but not in others (Light et al., 2009, Tchivileva et al., 2010). It is likely that some of these neurobiologic alterations are shared with other syndromes that are known to be associated with HPA and/or autonomic function such as depression or PTSD. In fact, this has led some who have superficially reviewed the neurobiologic data regarding fibromyalgia to conclude erroneously that this condition shares many biologic underpinnings with depression. ${ }^{34}$

Animal studies have directly tested if stress can enhance the response to painful stimuli, and if painful stimuli can alter the autonomic nervous system. Induction of stress in animals (swim stress, cold stress) can itself produce muscle and cutanoeus hyperalgesia that lasts for weeks after the stressor (Quintero et al., 2000, Quintero et al., 2003, Suarez-Roca et al., 2006, Nasu et al., 2010, Nishiyori et al., 2011). On the other hand, milder stressors (fatigue, sound stress) that do not produce hyperalgesia on their own, can enhance and prolong the hyperalgesic response to a subthreshold or mild noxious stimulus (Yokoyama et al., 2007b, Khasar et al., 2009, Sluka and Rasmussen, 2010, Sluka et al., 2012, Gregory et al., 2013). The hyperalgesia responses can be local to the site of noxious stimulus, but also widespread affecting the contralateral limb, or viscera (Yokoyama et al., 2007b, Green et al., 2011a, Green et al., 2011b, Gregory et al., 2013), and are more pronounced in female mice (Sluka and Rasmussen, 2010, Gregory et al., 2013). Further animals show increases in the anxiety index on the elevated plus maze suggesting animals show a co-morbid anxiety (Green et al., 
2011b). On the other hand, induction of chronic widespread pain in animals can alter autonomic function with decreased baroreflex sensitivity, increased blood pressure variability and decreased heart rate variability (Oliveira et al., 2012, Sabharwal et al., 2015). Together these symptoms of widespread hyperalgesia (paw, viscera, jaw), and anxiety mimic clinical symptoms and co-morbidities in fibromyalgia who have widespread pain, and a higher incidence of irritable bowel syndrome, temporomandibular disorder, autonomic dysfunction, and anxiety.

The stressor can lead to increases in plasma cortisone levels (Nishiyori et al., 2011) or longlasting increased activity of catecholamine synthesizing enzymes in the adrenal medulla (Khasar et al., 2008, Khasar et al., 2009) that results in increased plasma levels of epinephrine for at least 28 days after the last exposure to sound stress (Khasar et al., 2009) suggesting that a long-lasting stress-induced alteration in the animal that persists well beyond exposure to the starting stress factor. Decreasing expression of interleukin-6 receptor (IL-6) on primary afferent neurons prevents the enhanced response to noxious stimuli (Dina et al., 2011a) suggesting alterations in cytokines and the HPA axis may underlie stressinduced enhancement of hyperalgesia. Animals exposed to stressors also show changes in the spinal cord these models with enhanced c-fos expression in response to formalin, decreased basal and evoked release of the inhibitory neurotransmitter GABA, decreases in mu-opioid agonist antinociception enhanced basal and evoked release of glutamate (Omiya et al., 2000, Quintero et al., 2003, Suarez-Roca et al., 2008, Quintero et al., 2011), suggesting both enhanced central excitability and reduced central inhibition. In fact, stressinduced hyperalgesia is reduced by spinal blockade of substance $\mathrm{P}$, calcitonin-gene-related peptide (CGRP), NMDA-glutamate receptors and neurokinin-1 receptors, all substances implicated neurotransmission of pain (Satoh et al., 1992, Kuraishi and Satoh, 1993, Okano et al., 1995, Sluka et al., 2012). Supraspinally, cold-stress-induced alterations in the serotonergic system with reductions of both serotonin (5-HT) and 5-hydroxy indoleacetic acid (5-HIAA) levels in supraspinal regions such as hypothalamus, thalamus, midbrain, pons plus medulla oblongata in repeatedly cold-stressed rats (Hata et al., 1991). Thus, stress in combination with muscle insult produces widespread pain, is enhanced in females and alters central nervous system processing of nociceptive stimuli.

\section{Alterations in nociceptors may underlie some of the pathology in fibromyalgia}

\section{Human Studies}

While there is a general hypothesis that fibromyalgia is a 'central pain disorder;' several reports show evidence of peripheral nerve abnormalities in people with fibromyalgia. Specifically several studies report reduced numbers of epidermal nerve fibers in skin biopsies in people with fibromyalgia compared to healthy controls (Oaklander et al., 2013, Uceyler et al., 2013, Caro and Winter, 2014, Doppler et al., 2015). Individuals with fibromyalgia also have increased scores on neuropathic pain questionnaires, alterations in cold and warm detection thresholds measured by QST, and impaired pain-evoked responses (Oaklander et al., 2013, Uceyler et al., 2013). Rice and colleagues compared those with fibromyalgia to healthy controls and show in skin biopsies over the hypothenar eminence 
there is an increased size and innervation of arteriole venule shunts (AVS)(Albrecht et al., 2013). Using microneurography, Serra and colleagues show that mechanically-insensitive Cfibers show enhanced spontaneous activity and sensitization to mechanical stimulation (Serra et al., 2014). Further injection of lidocaine into muscles of people with fibromyalgia significantly reduced local hyperalgesia at the site of injection, hyperalgesia outside the site of injection, and decreased pain by $38 \%$ (Staud et al., 2014). Thus, peripheral factors may underlie some of the pain experienced by people with fibromyalgia. However, it is not clear if these factors are the primary cause or secondary to the condition itself.

While early studies did not see consistent changes in muscle tissue in individuals with fibromyalgia, more recent studies have begun to examine the muscle in more details. As in earlier studies, there are no differences in percent of Type I or Type II fiber types, the mean cross sectional area between groups, or the mean capillary density, between those with fibromyalgia and healthy controls (Srikuea et al., 2013). However, individuals with fibromyalgia showed fatigue resistance was strongly correlated with the size of Type I muscle fibers and hemoglobin oxygenation, and those with the highest percentage of Type I muscle fibers recovered strength most effectively, and correlated with capillary density. The authors suggest these measures might relate to the fatigue of fibromyalgia. Furthermore there are alterations in muscle oxygen utilization in individuals with fibromyalgia (Shang et al., 2012). Interestingly, there are no differences in performance or muscle fatigue measures in individuals with fibromyalgia compared to healthy controls, yet these women self-report enhanced fatigue and increased pain to a given fatiguing exercise task (Shang et al., 2012, Dailey et al., 2015). The differences in self-reported fatigue have generally thought to be of central origin, in part because this symptom often responds to CNS-acting drugs, but more recent data suggests that changes in the muscle tissue itself might contribute to this symptom.

\section{Animal Studies}

In humans, intramuscular infusion of an acidic solution ( $\mathrm{pH}$ 5.2) into the tibialis anterior muscle of the leg produces local muscle pain at the site of infusion and referred pain at the ankle (Frey Law et al., 2008). The acid infusion also results in decreased pressure pain thresholds at the site of infusion and in the referred pain area at the ankle showing that infusion of acid can produce primary and secondary hyperalgesia. These data suggest decreases in $\mathrm{pH}$ can contribute to the generation of referred hyperalgesia and pain.

Decreases in $\mathrm{pH}$, protons, can activate acid sensing ion channels (ASICs) on the peripheral terminals of nociceptors (for review see Abdelhamid and Sluka, 2015, Sluka and Gregory, 2015). Indeed ASIC3 is located on sensory neurons, sensory neurons innervating skeletal muscle express more ASIC3 than those innervating the skin, and 80\% of these ASIC3 positive skeletal muscle afferents co-express the nociceptive marker CGRP (Price et al., 2001, Molliver et al., 2005, Walder et al., 2011). As outlined above, two injections of acidic saline into a single gastrocnemius muscle produce hyperalgesia not only at the site of injection but also in the contralateral muscle and viscera. Pharmacological blockade of ASIC3, with APETx2, at the first or second injection, prevents the development of the widespread long-lasting hyperalgesia (Karczewski et al., 2010, Chen and Chen, 2014, Gregory et al., 2015b), suggesting activation of ASIC3 on nociceptors innervating muscle is 
important for development of widespread hyperalgesia (Figure 3). Similarly, the hyperalgesia in the repeated acid model, or the fatigue-induced model, requires activation of acid sensing ion channel 3 (ASIC3) since the hyperalgesia does not in ASIC3 knockout mice (Sluka et al., 2003, Gregory et al., 2015a)(Figure 3). However, when an ASIC antagonist is given after the development of hyperalgesia, there is no effect on the hyperalgesia, suggesting that once developed the hyperalgesia is independent of nociceptor activation by acidic pH (Karczewski et al., 2010, Gautam et al., 2012). On the other hand, in the reserpine-model of hyperalgesia there is increased expression of ASIC3 mRNA in DRG, the hyperalgesia is reversed by blockade of ASICs systemically with APETx2, and there are enhanced mechanical responsiveness of C-fibers in both the skin and muscle (Taguchi et al., 2015), suggesting that peripherally located ASIC3 could modulate widespread hyperalgesia. In fact the enhanced responsiveness of C-fibers in the skin is similar to that observed in individuals with fibromyalgia described above, and thus suggests ASIC3 could modulate the altered peripheral sensitivity.

In the non-inflammatory pain model, hyperalgesia is enhanced in mice that do not express the substance P and neurokinin A (tac1-/-), and activation of the NK1 receptor at the time of induction of the model prevented the long-lasting hyperalgesia. This is likely a result of inhibition of acid currents and is supported by the fact that substance P is found in ASIC3expressing neurons and inhibits acid-induced currents (Lin et al., 2012). Thus, by inhibiting substance P, could enhance neuronal excitability through ASIC3 and enhance pain by working peripherally on muscle afferents. This is directly in contrast to its actions in other tissues, and in the central nervous system and may explain part of the failure of substance $\mathrm{P}$ drugs on pain.

Nerve growth factor (NGF) is another potential mediator that could be involved in chronic muscle pain. It is synthesized in skeletal muscle (Amano et al., 1991), and its synthesis increases when the muscle is pathologically altered (Wu et al., 2009, Hayashi et al., 2011). Injection of NGF into the masseter and anterior tibialis muscle in humans results in a delayed onset of muscle hyperalgesia, but does not result in spontaneous pain (Svensson et al., 2003). Similarly, intramuscular NGF results in development of hyperalgesia in response to a single injection. This hyperalgesia is abolished by a systemic block of NMDA glutamate receptors, indicating a role for glutamate in the effects of NGF. Peripherally, approximately $60 \%$ of nociceptive group IV muscle afferents in rats are excited by NGF and NGF sensitizes nociceptors to peripherally applied noxious stimuli (Hoheisel et al., 2007, Murase et al., 2010, Rukwied et al., 2010). Interestingly, NGF produces central sensitization of dorsal horn neurons (Hoheisel et al., 2007). A prior injection of NGF (1 day before) results in a much stronger effect from a second NGF injection with significant increases in the number of neurons responding with action potentials, increased frequency of firing, and enhanced response to noxious stimuli. Thus, NGF-induced input changes the responsiveness of dorsal horn neurons to electrical stimulation within minutes, inducing sensitization to both noxious and innocuous intensities of mechanical stimulation. 


\section{Altered immune function might also contribute to some of the pathology in fibromyalgia}

\section{Animal and human studies}

Chronic systemic inflammation has been suggested to underlie the pathology in fibromyalgia and other chronic pain conditions (Slade et al., 2011, Sturgill et al., 2014, Mendieta et al., 2016). Immune cells are highly plastic, can alter levels of cytokines systemically or locally in tissue, and secrete inflammatory or anti-inflammatory cytokines based on their phenotype. In support, people with fibromyalgia show enhanced circulating inflammatory cytokines and enhanced evoked-release of inflammatory cytokines from circulating immune cells (Bote et al., 2013a, b, Mendieta et al., 2016). However, the literature on cytokines in fibromyalgia has been variable with some studies showing increases, some decreases, and some unchanged. Based on systematic reviews in people with fibromyalgia, there are consistent increases in IL-1Ra, IL-6 and IL-8 in serum (Uceyler et al., 2011), but mixed results for evoked-release of cytokines from peripheral blood mononuclear cells (PBMCs)(Menzies and Lyon, 2010). These reviews cite several limitations including low sample size, use of a mixed population of PBMCs, different stimulants to evoke cytokine release, and different analysis methods.

It is well established that the immune system, and factors released from immune cells such as cytokines play a critical role in the generation of both acute and chronic pain. Evidence for mast cells, neutrophils, macrophages, dendritic cells and T-cells show their involvement in a variety of pain conditions (Dawes et al., 2013). In animals, recent work has shown that resident macrophages located in muscle contribute to the development of chronic widespread muscle pain. For example removal of macrophages at the site of acid injection, with local injection clodronate liposomes, prevents the development of exercise-induced hyperalgesia (Gregory et al., 2015b)(Figure 3). On the other hand, pro-inflammatory cytokines, interleukins (IL-1 $\beta$, IL-6) and tumor necrosis factor (TNFa), can activate and sensitize nociceptors, produce pain in human subjects, and produce hyperalgesia in animals. Furthermore, the inflammatory cytokine IL-6 primes the muscle to respond in a more longlasting manner to a subsequent insult, intrmuscular prostaglandin-E2 when compared to naive animals injected with prostaglandin-E2 (Dina et al., 2008), and the inflammatory cytokines may also underlie the stress-induced enhancement of muscle pain described above (Dina et al., 2011b). Another potential source of such cytokines is adipose tissue, and there are many studies now begining to suggest that widespread or multifocal pain is more common in obese individuals (Cicuttini and Wluka, 2016), and obese animals show enhanced nociceptive responses (Rossi et al., 2013a, Rossi et al., 2013b). Thus, proinflammatory cytokines might play a role in the generation and enhancement of chronic muscle pain including fibromyalgia.

\section{Summary}

Although fibromyalgia and other chronic overlapping pain conditions have historically defied explanation based on "peripheral" theories of pain, it is now clear that these disorders have significant alterations in central nervous system factors leading to augmented pain and 
sensory processing. There may also be alterations in the immune system leading to an enhanced inflammatory state, and there are a number of other behaviors such as sleep dysfunction, mood difficulties, and fatigue that contribute to the pain and dysfunction in individuals with fibromyalgia. These same findings have been noted in animal models that lead to diffuse hyperalgesia and allodynia, and many of these same behaviors, yet are not characterized by ongoing peripheral nociceptive input. Emerging evidence suggests that some of the pathobiology in fibromyalgia may involve altered nociceptor sensitivity, and studies in some animal models of fibromyalgia indeed suggest altered nociceptor sensitivity is important for the induction of hyperalgesia and potentially the maintenance. However other animal models are independent of nociceptor input and suggest that the central nervous system maintains the hyperalgesia. We suggest that fibromyalgia is a heterogenous condition which likely has multiple potential etiologies. However, there is strong evidence, that there is a central nervous system component to the pain and symptoms associated that occurs in the majority of individuals with fibromyalgia.

It is most important to not think of fibromyalgia as "yes" or "no" but rather as the end of a continuum. This continuum on one end is a purely peripherally driven painful condition and responsive to treatments aimed at the periphery. Many chronic pain patients, including some individuals with fibromyalgia, on this continuum will have a mix of both peripheral nociceptive augmentation as well as centrally driven augmentation. The other end of the continuum is when pain is nearly completely the result of altered central augmentation. This central augmentation manifests as enhanced sensitivity to sensory stimuli, widespread pain, fatigue, sleep dysfunction, among other symptoms. In fact, many clinical studies suggest that various individuals with chronic pain, including fibromyalgia, are at various points in this continuum, and thus some may have a stronger peripheral than central components, some mixed peripheral and central components, and many have stronger central components. The further individuals are on this continuum - the more pain and other related symptoms they will experience for a given amount of nociceptive input.

It is important to understand where individuals with chronic pain are on this continuum since the most effective pharmacological treatments for acute nociceptive pain do not work for centralized pain. Once centralized, pharmacological and non-pharmacological treatments aimed at bringing these CNS neurotransmitter systems into balance, as well as therapies aimed at co-morbid symptoms need to be used. Therapies that focus on restoring sleep, and reducing stress and anxiety are critical to making a significant impact on pain and function need to be considered for all individuals. It is important to understand both the peripheral and central contributions in individuals with chronic pain so that therapies can be targeted toward both peripheral and central components, as well as accompanying co-morbid conditions such as anxiety.

\section{References}

Abdelhamid RE, Sluka KA. ASICs Mediate Pain and Inflammation in Musculoskeletal Diseases. Physiology(Bethesda). 2015; 30:449-459. [PubMed: 26525344]

Ablin JN, Clauw DJ, Lyden AK, Ambrose K, Williams DA, Gracely RH, Glass JM. Effects of sleep restriction and exercise deprivation on somatic symptoms and mood in healthy adults. Clin Exp Rheumatol. 2013; 31:S53-59. [PubMed: 24373363] 
Albrecht PJ, Hou Q, Argoff CE, Storey JR, Wymer JP, Rice FL. Excessive peptidergic sensory innervation of cutaneous arteriole-venule shunts (AVS) in the palmar glabrous skin of fibromyalgia patients: implications for widespread deep tissue pain and fatigue. Pain Med. 2013; 14:895-915. [PubMed: 23691965]

Amano T, Yamakuni T, Okabe N, Sakimura K, Takahashi Y. Production of nerve growth factor in rat skeletal muscle. Neurosci Lett. 1991; 132:5-7. [PubMed: 1724069]

Baidya DK, Agarwal A, Khanna P, Arora MK. Pregabalin in acute and chronic pain. J Anaesthesiol Clin Pharmacol. 2011; 27:307-314. [PubMed: 21897498]

Baraniuk JN, Whalen G, Cunningham J, Clauw DJ. Cerebrospinal fluid levels of opioid peptides in fibromyalgia and chronic low back pain. BMC Musculoskelet Disord. 2004; 5:48. [PubMed: 15588296]

Bement MK, Sluka KA. Low-intensity exercise reverses chronic muscle pain in the rat in a naloxonedependent manner. Arch Phys Med Rehabil. 2005; 86:1736-1740. [PubMed: 16181935]

Bement MK, Sluka KA. Co-localization of p-CREB and p-NR1 in spinothalamic neurons in a chronic muscle pain model. Neuroscience Letters. 2007; 418:22-27. [PubMed: 17395373]

Bobinski F, Ferreira TA, Cordova MM, Dombrowski PA, da CC, Santo CC, Poli A, Pires RG, MartinsSilva C, Sluka KA, Santos AR. Role of brainstem serotonin in analgesia produced by low-intensity exercise on neuropathic pain after sciatic nerve injury in mice. Pain. 2015; 156:2595-2606. [PubMed: 26447701]

Bote ME, Garcia JJ, Hinchado MD, Ortega E. An exploratory study of the effect of regular aquatic exercise on the function of neutrophils from women with fibromyalgia: Role of IL-8 and noradrenaline. Brain Behav Immun. 2013a

Bote ME, Garcia JJ, Hinchado MD, Ortega E. Fibromyalgia: anti-inflammatory and stress responses after acute moderate exercise. PLoS One. 2013b; 8:e74524. [PubMed: 24023948]

Brummett CM, Janda AM, Schueller CM, Tsodikov A, Morris M, Williams DA, Clauw DJ. Survey criteria for fibromyalgia independently predict increased postoperative opioid consumption after lower-extremity joint arthroplasty: a prospective, observational cohort study. Anesthesiology. 2013; 119:1434-1443. [PubMed: 24343289]

Carli G, Suman AL, Biasi G, Marcolongo R. Reactivity to superficial and deep stimuli in patients with chronic musculoskeletal pain. Pain. 2002; 100:259-269. [PubMed: 12467997]

Caro XJ, Winter EF. Evidence of abnormal epidermal nerve fiber density in fibromyalgia: clinical and immunologic implications. Arthritis \& rheumatology. 2014; 66:1945-1954. [PubMed: 24719395]

Chen WK, Liu IY, Chang YT, Chen YC, Chen CC, Yen CT, Shin HS. Ca(v)3.2 T-type Ca2+ channeldependent activation of ERK in paraventricular thalamus modulates acid-induced chronic muscle pain. J Neurosci. 2010a; 30:10360-10368. [PubMed: 20685979]

Chen WK, Liu IY, Chang YT, Chen YC, Chen CC, Yen CT, Shin HS, Chen CC. Ca(v)3.2 T-type Ca2+ channel-dependent activation of ERK in paraventricular thalamus modulates acid-induced chronic muscle pain. J NEUROSCI. 2010b; 30:10360-10368. [PubMed: 20685979]

Chen WN, Chen CC. Acid mediates a prolonged antinociception via substance P signaling in acidinduced chronic widespread pain. Mol Pain. 2014; 10:30. [PubMed: 24886508]

Cheng SJ, Chen CC, Yang HW, Chang YT, Bai SW, Chen CC, Yen CT, Min MY. Role of extracellular signal-regulated kinase in synaptic transmission and plasticity of a nociceptive input on capsular central amygdaloid neurons in normal and acid-induced muscle pain mice. J NEUROSCI. 2011; 31:2258-2270. [PubMed: 21307262]

Cicuttini FM, Wluka AE. Not just loading and age: the dynamics of osteoarthritis, obesity and inflammation. Med J Aust. 2016; 204:47. [PubMed: 26821091]

Clauw DJ. Fibromyalgia: a clinical review. JAMA. 2014; 311:1547-1555. [PubMed: 24737367]

Clauw DJ, Chrousos GP. Chronic pain and fatigue syndromes: overlapping clinical and neuroendocrine features and potential pathogenic mechanisms. Neuroimmunomodulation. 1997; 4:134-153. [PubMed: 9500148]

Coghill RC, McHaffie JG, Yen YF. Neural correlates of interindividual differences in the subjective experience of pain. Proc Natl Acad Sci USA. 2003; 100:8538-8542. [PubMed: 12824463] 
Cohen SP, Verdolin MH, Chang AS, Kurihara C, Morlando BJ, Mao J. The intravenous ketamine test predicts subsequent response to an oral dextromethorphan treatment regimen in fibromyalgia patients. J Pain. 2006; 7:391-398. [PubMed: 16750795]

Crofford L. The hypothalamic-pituitary-adrenal stress axis in the fibromyalgia syndrome. Journal of Musculoskeletal Pain. 1996; 4:181-200.

Crofford LJ. The hypothalamic-pituitary-adrenal axis in the pathogenesis of rheumatic diseases. Endocrinology and metabolism clinics of North America. 2002; 31:1-13. [PubMed: 12055982]

da Silva LFS, DeSantana JM, Sluka KA. Activation of NMDA receptors in the brainstem, rostral ventromedial medulla, and nucleus reticularis gigantocellularis mediates mechanical hyperalgesia produced by repeated intramuscular injections of acidic saline in rats. Pain. 2010a; 11:378-387.

da Silva LFS, Walder RY, Davidson BL, Wilson SP, Sluka KA. Changes in expression of NMDA-NR1 receptor subunits in the rostral ventromedial medulla modulates pain behaviors. Pain. 2010b; 151:155-161. [PubMed: 20688433]

Dailey DL, Keffala VJ, Sluka KA. Cognitive and physical fatigue tasks enhance pain, cognitive fatigue and physical fatigue in people with fibromyalgia. Arthritis Care Res (Hoboken). 2015; 67:288296. [PubMed: 25074583]

Dailey DL, Rakel BA, Vance CG, Liebano RE, Amrit AS, Bush HM, Lee KS, Lee JE, Sluka KA. Transcutaneous electrical nerve stimulation reduces pain, fatigue and hyperalgesia while restoring central inhibition in primary fibromyalgia. Pain. 2013; 154:2554-2562. [PubMed: 23900134]

Dawes, JM.; Andersson, DA.; Bennett, DLH.; Bevan, S.; McMahon, SB. Inflammatory Mediators and Modulators of Pain. In: McMahon, SB., et al., editors. Melzack and Wall's Textbook of Pain. 6. Philadelphia: Elsevier; 2013. p. 48

De Resende MA, Silva LF, Sato K, Arendt-Nielsen L, Sluka KA. Blockade of Opioid Receptors in the Medullary Reticularis Nucleus Dorsalis, but not the Rostral Ventromedial Medulla, Prevents Analgesia Produced by Diffuse Noxious Inhibitory Control in Rats With Muscle Inflammation. J Pain. 2011

Desmeules JA, Cedraschi C, Rapiti E, Baumgartner E, Finckh A, Cohen P, Dayer P, Vischer TL. Neurophysiologic evidence for a central sensitization in patients with fibromyalgia. Arthritis Rheum. 2003; 48:1420-1429. [PubMed: 12746916]

Dickenson AH, Sullivan AF. Evidence for a role of the NMDA receptor in the frequency dependent potentiation of deep rat dorsal horn nociceptive neurones following $\mathrm{C}$ fibre stimulation. Neuropharmacology. 1987; 26:1235-1238. [PubMed: 2821443]

Dina OA, Levine JD, Green PG. Muscle inflammation induces a protein kinase Cepsilon-dependent chronic-latent muscle pain. J Pain. 2008; 9:457-462. [PubMed: 18342576]

Dina OA, Levine JD, Green PG. Enhanced cytokine-induced mechanical hyperalgesia in skeletal muscle produced by a novel mechanism in rats exposed to unpredictable sound stress. European journal of pain. 2011a

Dina OA, Levine JD, Green PG. Enhanced cytokine-induced mechanical hyperalgesia in skeletal muscle produced by a novel mechanism in rats exposed to unpredictable sound stress. Eur J Pain. 2011b; 15:796-800. [PubMed: 21419675]

Dohrenbusch R, Sodhi H, Lamprecht J, Genth E. Fibromyalgia as a disorder of perceptual organization? An analysis of acoustic stimulus processing in patients with widespread pain. Zeitschrift fur Rheumatologie. 1997; 56:334-341. [PubMed: 9487649]

Doppler K, Rittner HL, Deckart M, Sommer C. Reduced dermal nerve fiber diameter in skin biopsies of patients with fibromyalgia. Pain. 2015; 156:2319-2325. [PubMed: 26164586]

Eippert F, Tracey I. Pain and the PAG: learning from painful mistakes. Nat Neurosci. 2014; 17:14381439. [PubMed: 25349908]

Fayed N, Garcia-Campayo J, Magallon R, Andres-Bergareche H, Luciano JV, Andres E, Beltran J. Localized 1H-NMR spectroscopy in patients with fibromyalgia: a controlled study of changes in cerebral glutamate/glutamine, inositol, choline, and N-acetylaspartate. Arthritis Res Ther. 2010; 12:R134. [PubMed: 20609227]

Foerster BR, Nascimento TD, DeBoer M, Bender MA, Rice IC, Truong DQ, Bikson M, Clauw DJ, Zubieta JK, Harris RE, DaSilva AF. Excitatory and inhibitory brain metabolites as targets of motor 
cortex transcranial direct current stimulation therapy and predictors of its efficacy in fibromyalgia. Arthritis \& rheumatology. 2015; 67:576-581. [PubMed: 25371383]

Frey Law LA, Sluka KA, McMullen T, Lee J, Arendt-Nielsen L, Graven-Nielsen T. Acidic buffer induced muscle pain evokes referred pain and mechanical hyperalgesia in humans. Pain. 2008; 140:254-264. [PubMed: 18835099]

Gautam M, Benson CJ, Ranier JD, Light AR, Sluka KA. ASICs do not play a role in maintaining hyperalgesia induced by repeated intramuscular acid injections. Pain Res Treat. 2012; 2012:817437.

Geisser ME, Glass JM, Rajcevska LD, Clauw DJ, Williams DA, Kileny PR, Gracely RH. A psychophysical study of auditory and pressure sensitivity in patients with fibromyalgia and healthy controls. J Pain. 2008; 9:417-422. [PubMed: 18280211]

Gerecz-Simon EM, Tunks ER, Heale JA, Kean WF, Buchanan WW. Measurement of pain threshold in patients with rheumatoid arthritis, osteoarthritis, ankylosing spondylitis, and healthy controls [see comments]. Clinical Rheumatology. 1989; 8:467-474. [PubMed: 2612115]

Gerster JC, Hadj-Djilani A. Hearing and vestibular abnormalities in primary fibrositis syndrome. Journal of Rheumatology. 1984; 11:678-680. [PubMed: 6595407]

Giesecke T, Gracely RH, Grant MA, Nachemson A, Petzke F, Williams DA, Clauw DJ. Evidence of augmented central pain processing in idiopathic chronic low back pain. Arthritis Rheum. 2004; 50:613-623. [PubMed: 14872506]

Giesecke T, Gracely RH, Williams DA, Geisser M, Petzke F, Clauw DJ. The relationship between depression, clinical pain, and experimental pain in a chronic pain cohort. Arthritis \& Rheumatism. 2005:52.

Glass JM, Lyden A, Petzke F, Clauw D. The effect of brief exercise cessation on pain, fatigue, and mood symptom development in healthy, fit individuals. Journal of Psychosomatic Research. 2004; 57:391-398. [PubMed: 15518675]

Gracely RH, Geisser ME, Giesecke T, Grant MA, Petzke F, Williams DA, Clauw DJ. Pain catastrophizing and neural responses to pain among persons with fibromyalgia. Brain. 2004; 127:835-843. [PubMed: 14960499]

Gracely RH, Petzke F, Wolf JM, Clauw DJ. Functional magnetic resonance imaging evidence of augmented pain processing in fibromyalgia. Arthritis Rheum. 2002; 46:1333-1343. [PubMed: 12115241]

Graven-Nielsen T, Aspegren KS, Henriksson KG, Bengtsson M, Sorensen J, Johnson A, Gerdle B, Arendt-Nielsen L. Ketamine reduces muscle pain, temporal summation, and referred pain in fibromyalgia patients. Pain. 2000; 85:483-491. [PubMed: 10781923]

Green PG, Alvarez P, Gear RW, Mendoza D, Levine JD. Further validation of a model of fibromyalgia syndrome in the rat. J Pain. 2011a; 12:811-818. [PubMed: 21481648]

Green PG, Chen X, Alvarez P, Ferrari LF, Levine JD. Early-life stress produces muscle hyperalgesia and nociceptor sensitization in the adult rat. Pain. 2011b; 152:2549-2556. [PubMed: 21864980]

Gregory NS, Brito R, Fusaro MCGO, Sluka KA. ASIC3 is required for development of fatigueinduced hyperalgesia. Mol Neurobiol. 2015a

Gregory NS, Brito R, Fusaro MCGO, Sluka KA. ASIC3 is required for development of fatigueinduced hyperalgesia. Molecular neurobiology. 2015b; 53:10.

Gregory NS, Gibson-Corley K, Frey-Law L, Sluka KA. Fatigue-enhanced hyperalgesia in response to muscle insult: Induction and development occur in a sex-dependent manner. Pain. 2013; 154:2668-2676. [PubMed: 23906552]

Gwilym SE, Filippini N, Douaud G, Carr AJ, Tracey I. Thalamic atrophy associated with painful osteoarthritis of the hip is reversible after arthroplasty: a longitudinal voxel-based morphometric study. Arthritis and Rheumatism. 2010; 62:2930-2940. [PubMed: 20518076]

Gwilym SE, Oag HC, Tracey I, Carr AJ. Evidence that central sensitisation is present in patients with shoulder impingement syndrome and influences the outcome after surgery. J Bone Joint Surg Br. 2011; 93:498-502. [PubMed: 21464489]

Harris RE. Elevated excitatory neurotransmitter levels in the fibromyalgia brain. Arthritis Res Ther. 2010; 12:141. [PubMed: 20959024] 
Harris RE, Clauw DJ. Imaging central neurochemical alterations in chronic pain with proton magnetic resonance spectroscopy. Neurosci Lett. 2012; 520:192-196. [PubMed: 22445845]

Harris RE, Clauw DJ, Scott DJ, McLean SA, Gracely RH, Zubieta JK. Decreased central mu-opioid receptor availability in fibromyalgia. J Neurosci. 2007; 27:10000-10006. [PubMed: 17855614]

Harris RE, Napadow V, Huggins JP, Pauer L, Kim J, Hampson J, Sundgren PC, Foerster B, Petrou M, Schmidt-Wilcke T, Clauw DJ. Pregabalin rectifies aberrant brain chemistry, connectivity, and functional response in chronic pain patients. Anesthesiology. 2013; 119:1453-1464. [PubMed: 24343290]

Harris RE, Sundgren PC, Craig AD, Kirshenbaum E, Sen A, Napadow V, Clauw DJ. Elevated insular glutamate in fibromyalgia is associated with experimental pain. Arthritis Rheum. 2009; 60:31463152. [PubMed: 19790053]

Harris RE, Sundgren PC, Pang Y, Hsu M, Petrou M, Kim SH, McLean SA, Gracely RH, Clauw DJ. Dynamic levels of glutamate within the insula are associated with improvements in multiple pain domains in fibromyalgia. Arthritis Rheum. 2008; 58:903-907. [PubMed: 18311814]

Harte SE, Clauw DJ, Napadow V, Harris RE. Pressure Pain Sensitivity and Insular Combined Glutamate and Glutamine (Glx) Are Associated with Subsequent Clinical Response to Sham But Not Traditional Acupuncture in Patients Who Have Chronic Pain. Med Acupunct. 2013; 25:154160. [PubMed: 24761170]

Hata T, Itoh E, Kawabata A. Changes in CNS levels of serotonin and its metabolite in SART-stressed (repeatedly cold-stressed) rats. Jpn J Pharmacol. 1991; 56:101-104. [PubMed: 1715412]

Hayashi K, Ozaki N, Kawakita K, Itoh K, Mizumura K, Furukawa K, Yasui M, Hori K, Yi SQ, Yamaguchi T, Sugiura Y. Involvement of NGF in the rat model of persistent muscle pain associated with taut band. J Pain. 2011; 12:1059-1068. [PubMed: 21719352]

Hoeger-Bement MK, Sluka KA. Phosphorylation of CREB and mechanical hyperalgesia is reversed by blockade of the cAMP pathway in a time-dependent manner after repeated intramuscular acid injections. Journal of Neuroscience. 2003; 23:5437-5445. [PubMed: 12843242]

Hoheisel U, Unger T, Mense S. Sensitization of rat dorsal horn neurons by NGF-induced subthreshold potentials and low-frequency activation. A study employing intracellular recordings in vivo. BRAIN RES. 2007; 1169:34-43. [PubMed: 17698048]

Holton KF, Taren DL, Thomson CA, Bennett RM, Jones KD. The effect of dietary glutamate on fibromyalgia and irritable bowel symptoms. Clin Exp Rheumatol. 2012; 30:10-17. [PubMed: 22766026]

Janda AM, As-Sanie S, Rajala B, Tsodikov A, Moser SE, Clauw DJ, Brummett CM. Fibromyalgia Survey Criteria Is Associated with Increased Postoperative Opioid Consumption in Women Undergoing Hysterectomy. Anesthesiology. 2015

Jensen KB, Loitoile R, Kosek E, Petzke F, Carville S, Fransson P, Marcus H, Williams SC, Choy E, Mainguy Y, Vitton O, Gracely RH, Gollub R, Ingvar M, Kong J. Patients with fibromyalgia display less functional connectivity in the brain's pain inhibitory network. Mol Pain. 2012; 8:32. [PubMed: 22537768]

Julien N, Goffaux P, Arsenault P, Marchand S. Widespread pain in fibromyalgia is related to a deficit of endogenous pain inhibition. Pain. 2005; 114:295-302. [PubMed: 15733656]

Karczewski J, Spencer RH, Garsky VM, Liang A, Leitl MD, Cato MJ, Cook SP, Kane S, Urban MO. Reversal of acid-induced and inflammatory pain by the selective ASIC3 inhibitor, APETx2. Br J Pharmacol. 2010; 161:950-960. [PubMed: 20860671]

Khasar SG, Burkham J, Dina OA, Brown AS, Bogen O, Alessandri-Haber N, Green PG, Reichling DB, Levine JD. Stress induces a switch of intracellular signaling in sensory neurons in a model of generalized pain. J Neurosci. 2008; 28:5721-5730. [PubMed: 18509033]

Khasar SG, Dina OA, Green PG, Levine JD. Sound stress-induced long-term enhancement of mechanical hyperalgesia in rats is maintained by sympathoadrenal catecholamines. J Pain. 2009; 10:1073-1077. [PubMed: 19576859]

Kim SH, Song J, Mun H, Park KU. Effect of the combined use of tramadol and milnacipran on pain threshold in an animal model of fibromyalgia. Korean J Intern Med. 2009; 24:139-142. [PubMed: 19543493] 
Kosek E, Ekholm J, Hansson P. Increased pressure pain sensibility in fibromyalgia patients is located deep to the skin but not restricted to muscle tissue. Pain. 1995; 63:335-339. [PubMed: 8719534]

Kosek E, Hansson P. Modulatory influence on somatosensory perception from vibration and heterotopic noxious conditioning stimulation (HNCS) in fibromyalgia patients and healthy subjects. Pain. 1997; 70:41-51. [PubMed: 9106808]

Kosek E, Ordeberg G. Lack of pressure pain modulation by heterotopic noxious conditioning stimulation in patients with painful osteoarthritis before, but not following, surgical pain relief. Pain. 2000; 88:69-78. [PubMed: 11098101]

Kroenke K, Mangelsdorff AD. Common symptoms in ambulatory care: Incidence, evaluation, therapy, and outcome. American Journal of Medicine. 1989; 86:262-266. [PubMed: 2919607]

Kuraishi Y, Satoh M. Participation of spinal cord substance P in hyperalgesia induced by repeated cold stress. Regul Pept. 1993; 46:405-406. [PubMed: 7692549]

Lautenbacher S, Rollman GB. Possible deficiencies of pain modulation in fibromyalgia. Clinical Journal of Pain. 1997; 13:189-196. [PubMed: 9303250]

Lautenbacher S, Rollman GB, McCain GA. Multi-method assessment of experimental and clinical pain in patients with fibromyalgia. Pain. 1994; 59:45-53. [PubMed: 7854801]

Le Bars D, Villanueva L. Electrophysiological evidence for the activation of descending inhibitory controls by nociceptive afferent pathways. Prog Brain Res. 1988; 77:275-299. [PubMed: 3064172]

Le Bars D, Villanueva L, Bouhassira D, Willer JC. Diffuse noxious inhibitory controls (DNIC) in animals and in man. Patol Fiziol Eksp Ter. 1992:55-65.

Lee MC, Tracey I. Imaging pain: a potent means for investigating pain mechanisms in patients. $\mathrm{Br} \mathbf{J}$ Anaesth. 2013; 111:64-72. [PubMed: 23794647]

Letzen JE, Craggs JG, Perlstein WM, Price DD, Robinson ME. Functional connectivity of the default mode network and its association with pain networks in irritable bowel patients assessed via lidocaine treatment. J Pain. 2013; 14:1077-1087. [PubMed: 23743257]

Light AR, White AT, Hughen RW, Light KC. Moderate exercise increases expression for sensory, adrenergic, and immune genes in chronic fatigue syndrome patients but not in normal subjects. $\mathrm{J}$ Pain. 2009; 10:1099-1112. [PubMed: 19647494]

Lin CC, Chen WN, Chen CJ, Lin YW, Zimmer A, Chen CC. An antinociceptive role for substance P in acid-induced chronic muscle pain. Proc Natl Acad Sci USA. 2012; 109:E76-E83. [PubMed: 22084095]

Liu YT, Shao YW, Yen CT, Shaw FZ. Acid-induced hyperalgesia and anxio-depressive comorbidity in rats. Physiol Behav. 2014; 131:105-110. [PubMed: 24726391]

Loggia ML, Kim J, Gollub RL, Vangel MG, Kirsch I, Kong J, Wasan AD, Napadow V. Default mode network connectivity encodes clinical pain: an arterial spin labeling study. Pain. 2013; 154:24-33. [PubMed: 23111164]

Martinez-Lavin M, Hermosillo AG. Autonomic nervous system dysfunction may explain the multisystem features of fibromyalgia [editorial; comment]. Seminars in Arthritis and Rheumatism. 2000; 29:197-199. [PubMed: 10707988]

Mayer EA, Gebhart GF. Basic and clinical aspects of visceral hyperalgesia. Gastroenterology. 1994; 107:271-293. [PubMed: 8020671]

McBeth J, Morris S, Benjamin S, Silman AJ, Macfarlane GJ. Associations between adverse events in childhood and chronic widespread pain in adulthood: are they explained by differential recall? J Rheumatol. 2001; 28:2305-2309. [PubMed: 11669174]

McLean SA, Williams DA, Stein PK, Harris RE, Lyden AK, Whalen G, Park KM, Liberzon I, Sen A, Gracely RH, Baraniuk JN, Clauw DJ. Cerebrospinal fluid corticotropin-releasing factor concentration is associated with pain but not fatigue symptoms in patients with fibromyalgia. Neuropsychopharmacology. 2006; 31:2776-2782. [PubMed: 16936702]

Mendieta D, la Cruz-Aguilera DL, Barrera-Villalpando MI, Becerril-Villanueva E, Arreola R, Hernandez-Ferreira E, Perez-Tapia SM, Perez-Sanchez G, Garces-Alvarez ME, Aguirre-Cruz L, Velasco-Velazquez MA, Pavon L. IL-8 and IL-6 primarily mediate the inflammatory response in fibromyalgia patients. J Neuroimmunol. 2016; 290:22-25. [PubMed: 26711564]

Menzies V, Lyon DE. Integrated review of the association of cytokines with fibromyalgia and fibromyalgia core symptoms. Biol Res Nurs. 2010; 11:387-394. [PubMed: 19933683] 
Miranda A, Peles S, McLean PG, Sengupta JN. Effects of the 5-HT3 receptor antagonist, alosetron, in a rat model of somatic and visceral hyperalgesia. Pain. 2006; 126:54-63. [PubMed: 16844296]

Miranda A, Peles S, Rudolph C, Shaker R, Sengupta JN. Altered visceral sensation in response to somatic pain in the rat. Gastroenterology. 2004; 126:1082-1089. [PubMed: 15057747]

Molliver DC, Immke DC, Fierro L, Pare M, Rice FL, McCleskey EW. ASIC3, an acid-sensing ion channel, is expressed in metaboreceptive sensory neurons. Molecular Pain. 2005; 1:35. [PubMed: 16305749]

Murase S, Terazawa E, Queme F, Ota H, Matsuda T, Hirate K, Kozaki Y, Katanosaka K, Taguchi T, Urai H, Mizumura K. Bradykinin and nerve growth factor play pivotal roles in muscular mechanical hyperalgesia after exercise (delayed-onset muscle soreness). J NEUROSCI. 2010; 30:3752-3761. [PubMed: 20220009]

Nagakura Y, Oe T, Aoki T, Matsuoka N. Biogenic amine depletion causes chronic muscular pain and tactile allodynia accompanied by depression: A putative animal model of fibromyalgia. Pain. 2009; 146:26-33. [PubMed: 19646816]

Napadow V, Kim J, Clauw DJ, Harris RE. Decreased intrinsic brain connectivity is associated with reduced clinical pain in fibromyalgia. Arthritis Rheum. 2012; 64:2398-2403. [PubMed: 22294427]

Napadow V, Lacount L, Park K, As-Sanie S, Clauw DJ, Harris RE. Intrinsic brain connectivity in fibromyalgia is associated with chronic pain intensity. Arthritis Rheum. 2010

Nasu T, Taguchi T, Mizumura K. Persistent deep mechanical hyperalgesia induced by repeated cold stress in rats. Eur J Pain. 2010; 14:236-244. [PubMed: 19560379]

Nielsen AN, Mathiesen C, Blackburn-Munro G. Pharmacological characterisation of acid-induced muscle allodynia in rats. European Journal of Pharmacology. 2004; 487:93-103. [PubMed: 15033380]

Nishiyori M, Uchida H, Nagai J, Araki K, Mukae T, Kishioka S, Ueda H. Permanent relief from intermittent cold stress-induced fibromyalgia-like abnormal pain by repeated intrathecal administration of antidepressants. Mol Pain. 2011; 7:69. [PubMed: 21933442]

Oaklander AL, Herzog ZD, Downs HM, Klein MM. Objective evidence that small-fiber polyneuropathy underlies some illnesses currently labeled as fibromyalgia. Pain. 2013; 154:2310-2316. [PubMed: 23748113]

Okano K, Kuraishi Y, Satoh M. Effects of intrathecally injected glutamate and substance P antagonists on repeated cold stress-induced hyperalgesia in rats. Biol Pharm Bull. 1995; 18:42-44. [PubMed: 7537576]

Olivan-Blazquez B, Herrera-Mercadal P, Puebla-Guedea M, Perez-Yus MC, Andres E, Fayed N, Lopez-Del-Hoyo Y, Magallon R, Roca M, Garcia-Campayo J. Efficacy of memantine in the treatment of fibromyalgia: A double-blind, randomised, controlled trial with 6-month follow-up. Pain. 2014; 155:2517-2525. [PubMed: 25218600]

Oliveira LR, de Melo VU, Macedo FN, Barreto AS, Badaue-Passos D Jr, Viana dos Santos MR, Dias DP, Sluka KA, DeSantana JM, Santana-Filho VJ. Induction of chronic non-inflammatory widespread pain increases cardiac sympathetic modulation in rats. Auton Neurosci. 2012; 167:45-49. [PubMed: 22266357]

Omiya Y, Goto K, Ishige A, Komatsu Y. Changes in analgesia-producing mechanism of repeated cold stress loading in mice. Pharmacol Biochem Behav. 2000; 65:261-266. [PubMed: 10672978]

Petzke F, Ambrose K, Gracely RH, Clauw DJ. What do tender points measure? Arthritis \& Rheumatism. 1999a; 42:S342.

Petzke F, Clauw DJ. Sympathetic nervous system function in fibromyalgia. Curr Rheumatol Rep. 2000; 2:116-123. [PubMed: 11123048]

Petzke F, Clauw DJ, Ambrose K, Khine A, Gracely RH. Increased pain sensitivity in fibromyalgia: effects of stimulus type and mode of presentation. Pain. 2003a; 105:403-413. [PubMed: 14527701]

Petzke F, Gracely RH, Khine A, Clauw DJ. Pain sensitivity in patients with fibromyalgia (FM): Expectancy effects on pain measurements. Arthritis \& Rheumatism. 1999b; 42:S342.

Petzke F, Gracely RH, Park KM, Ambrose K, Clauw DJ. What do tender points measure? Influence of distress on 4 measures of tenderness. J Rheumatol. 2003b; 30:567-574. [PubMed: 12610818] 
Petzke F, Khine A, Williams D, Groner K, Clauw DJ, Gracely RH. Dolorimetry performed at 3 paired tender points highly predicts overall tenderness. Journal of Rheumatology. 2001; 28:2568-2569. [PubMed: 11708444]

Pillemer SR, Bradley LA, Crofford LJ, Moldofsky H, Chrousos GP. The neuroscience and endocrinology of fibromyalgia. Arthritis \& Rheumatism. 1997; 40:1928-1939. [PubMed: 9365080]

Potvin S, Paul-Savoie E, Morin M, Bourgault P, Marchand S. Temporal summation of pain is not amplified in a large proportion of fibromyalgia patients. Pain Res Treat. 2012; 2012:938595. [PubMed: 22701791]

Price DD, Staud R, Robinson ME, Mauderli AP, Cannon R, Vierck CJ. Enhanced temporal summation of second pain and its central modulation in fibromyalgia patients. Pain. 2002; 99:49-59. [PubMed: 12237183]

Price MP, McIlwrath SL, Xie J, Cheng C, Qiao J, Tarr DE, Sluka KA, Brennan TJ, Lewin GR, Welsh MJ. The DRASIC cation channel contributes to the detection of cutaneous touch and acid stimuli in mice. Neuron. 2001; 32:1071-1083. [PubMed: 11754838]

Quintero J, Dooley DJ, Pomerleau F, Huettl P, Gerhardt G. Amperometric Measurement of Glutamate Release Modulation by Gabapentin and Pregabalin in Rat Neocortical Slices: Role of VoltageSensitive Ca2+ \{alpha\}2\{delta\}-1 Subunit. J Pharmacol Exp Ther. 2011

Quintero L, Cuesta MC, Silva JA, Arcaya JL, Pinerua-Suhaibar L, Maixner W, Suarez-Roca H. Repeated swim stress increases pain-induced expression of c-Fos in the rat lumbar cord. Brain research. 2003; 965:259-268. [PubMed: 12591144]

Quintero L, Moreno M, Avila C, Arcaya J, Maixner W, Suarez-Roca H. Long-lasting delayed hyperalgesia after subchronic swim stress. Pharmacology, biochemistry, and behavior. 2000; 67:449-458.

Radhakrishnan R, Sluka KA. Increased glutamate and decreased glycine release in the rostral ventromedial medulla during induction of a pre-clinical model of chronic widespread muscle pain. Neurosci Lett. 2009; 457:141-145. [PubMed: 19429181]

Raphael KG, Natelson BH, Janal MN, Nayak S. A community-based survey of fibromyalgia-like pain complaints following the World Trade Center terrorist attacks. Pain. 2002; 100:131-139. [PubMed: 12435466]

Roerig SC, Fujimoto JM, Tseng LF. Comparisons of descending pain inhibitory pathways activated by beta-endorphin and morphine as characterized by supraspinal and spinal antinociceptive interactions in mice. J Pharmacol Exp Ther. 1988; 247:1107-1113. [PubMed: 2974485]

Rossi HL, Luu AK, DeVilbiss JL, Recober A. Obesity increases nociceptive activation of the trigeminal system. European journal of pain. 2013a; 17:649-653. [PubMed: 23070979]

Rossi HL, Luu AK, Kothari SD, Kuburas A, Neubert JK, Caudle RM, Recober A. Effects of dietinduced obesity on motivation and pain behavior in an operant assay. Neuroscience. 2013b; 235:87-95. [PubMed: 23333672]

Rukwied R, Mayer A, Kluschina O, Obreja O, Schley M, Schmelz M. NGF induces non-inflammatory localized and lasting mechanical and thermal hypersensitivity in human skin. Pain. 2010; 148:407-413. [PubMed: 20022698]

Russell IJ. Neurochemical pathogenesis of fibromyalgia. Zeitschrift fur Rheumatologie. 1998; 57(Suppl 2):63-66. [PubMed: 10025086]

Russell IJ, Vaeroy H, Javors M, Nyberg F. Cerebrospinal fluid biogenic amine metabolites in fibromyalgia/fibrositis syndrome and rheumatoid arthritis. Arthritis \& Rheumatism. 1992; 35:550-556. [PubMed: 1374252]

Russell IJ, Vipraio G, Fletcher EM, Lopez YM, Orr MD, Michalek JE. Characteristics of spinal fluid (CSF) substance $\mathrm{p}$ (SP) and calcitonin gene related peptide (CGRP) in fibromyalgia syndrome (FMS). Arthritis \& Rheumatism. 1996; 39:S275.

Sabharwal R, Rasmussen L, Sluka KA, Chapleau MW. EXERCISE PREVENTS DEVELOPMENT OF AUTONOMIC DYSREGULATION AND HYPERALGESIA IN A MOUSE MODEL OF CHRONIC MUSCLE PAIN. Pain. 2015

Sarchielli P, Di Filippo M, Nardi K, Calabresi P. Sensitization, glutamate, and the link between migraine and fibromyalgia. Curr Pain Headache Rep. 2007; 11:343-351. [PubMed: 17894924] 
Satoh M, Kuraishi Y, Kawamura M. Effects of intrathecal antibodies to substance-P, calcitonin generelated peptide and galanin on repeated cold stress-induced hyperalgesia - comparison with carrageenan-induced hyperalgesia. Pain. 1992; 49:273-278. [PubMed: 1376888]

Schmidt-Wilcke T, Clauw DJ. Fibromyalgia: from pathophysiology to therapy. Nature reviews Rheumatology. 2011

Schmidt-Wilcke T, Ichesco E, Hampson JP, Kairys A, Peltier S, Harte S, Clauw DJ, Harris RE. Resting state connectivity correlates with drug and placebo response in fibromyalgia patients. Neuroimage Clin. 2014; 6:252-261. [PubMed: 25379438]

Schwarz MJ, Spath M, Muller-Bardorff H, Pongratz DE, Bondy B, Ackenheil M. Relationship of substance P, 5-hydroxyindole acetic acid and tryptophan in serum of fibromyalgia patients. Neuroscience Letters. 1999; 259:196-198. [PubMed: 10025591]

Segerdahl AR, Mezue M, Okell TW, Farrar JT, Tracey I. The dorsal posterior insula subserves a fundamental role in human pain. Nat Neurosci. 2015; 18:499-500. [PubMed: 25751532]

Serra J, Collado A, Sola R, Antonelli F, Torres X, Salgueiro M, Quiles C, Bostock H. Hyperexcitable C nociceptors in fibromyalgia. Ann Neurol. 2014; 75:196-208. [PubMed: 24243538]

Shang Y, Gurley K, Symons B, Long D, Srikuea R, Crofford LJ, Peterson CA, Yu G. Noninvasive optical characterization of muscle blood flow, oxygenation, and metabolism in women with fibromyalgia. Arthritis Res Ther. 2012; 14:R236. [PubMed: 23116302]

Sharma NK, Ryals JM, Gajewski BJ, Wright DE. Aerobic exercise alters analgesia and neurotrophin-3 synthesis in an animal model of chronic widespread pain. Phys Ther. 2010; 90:714-725. [PubMed: 20338916]

Sharma NK, Ryals JM, Liu H, Liu W, Wright DE. Acidic saline-induced primary and secondary mechanical hyperalgesia in mice. J Pain. 2009; 10:1231-1241. [PubMed: 19592308]

Simms RW, Roy SH, Hrovat M, Anderson JJ, Skrinar G, LePoole SR, Zerbini CA, de Luca C, Jolesz F. Lack of association between fibromyalgia syndrome and abnormalities in muscle energy metabolism [see comments]. Arthritis \& Rheumatism. 1994; 37:794-800. [PubMed: 8003050]

Skyba DA, King EW, Sluka KA. Effects of NMDA and non-NMDA ionotropic glutamate receptor antagonists on the development and maintenance of hyperalgesia induced by repeated intramuscular injection of acidic saline. Pain. 2002; 98:69-78. [PubMed: 12098618]

Skyba DA, Lisi TL, Sluka KA. Excitatory amino acid concentrations increase in the spinal cord dorsal horn after repeated intramuscular injection of acidic saline. Pain. 2005; 119:142-149. [PubMed: 16297556]

Slade GD, Conrad MS, Diatchenko L, Rashid NU, Zhong S, Smith S, Rhodes J, Medvedev A, Makarov S, Maixner W, Nackley AG. Cytokine biomarkers and chronic pain: association of genes, transcription, and circulating proteins with temporomandibular disorders and widespread palpation tenderness. Pain. 2011; 152:2802-2812. [PubMed: 22000099]

Sluka KA, Danielson J, Rasmussen L, Dasilva LF. Exercise-Induced Pain Requires NMDA Receptor Activation in the Medullary Raphe Nuclei. Med Sci Sports Exerc. 2012; 44:420-427. [PubMed: 21795998]

Sluka KA, Gregory NS. The dichotomized role for acid sensing ion channels in musculoskeletal pain and inflammation. Neuropharmacology. 2015; 94:58-63. [PubMed: 25582293]

Sluka KA, Kalra A, Moore SA. Unilateral intramuscular injections of acidic saline produce a bilateral, long-lasting hyperalgesia. Muscle \& Nerve. 2001; 24:37-46. [PubMed: 11150964]

Sluka KA, O’Donnell JM, Danielson J, Rasmussen LA. Regular physical activity prevents development of chronic pain and activation of central neurons. J Appl Physiol. 2013; 114:725733. [PubMed: 23271699]

Sluka KA, Price MP, Breese NM, Stucky CL, Wemmie JA, Welsh MJ. Chronic hyperalgesia induced by repeated acid injections in muscle is abolished by the loss of ASIC3, but not ASIC1. Pain. 2003; 106:229-239. [PubMed: 14659506]

Sluka KA, Rasmussen LA. Fatiguing exercise enhances hyperalgesia to muscle inflammation. Pain. 2010; 148:188-197. [PubMed: 19632780]

Sluka KA, Rohlwing JJ, Bussey RA, Eikenberry SA, Wilken JM. Chronic muscle pain induced by repeated acid injection is reversed by spinally administered $æ-$, and ë-, but not $\mathrm{k}-$, opioid receptor 
agonists. Journal of Pharmacology and Experimental Therapeutics. 2002; 302:1146-1150. [PubMed: 12183674]

Smythe H. Tender points: Evolution of concepts of the fibrositis/fibromyalgia syndrome. American Journal of Medicine. 1986; 81:2-6.

Sorensen J, Graven-Nielsen T, Henriksson KG, Bengtsson M, Arendt-Nielsen L. Hyperexcitability in fibromyalgia. Journal of Rheumatology. 1998; 25:152-155. [PubMed: 9458220]

Srikuea R, Symons TB, Long DE, Lee JD, Shang Y, Chomentowski PJ, Yu G, Crofford LJ, Peterson CA. Association of fibromyalgia with altered skeletal muscle characteristics which may contribute to postexertional fatigue in postmenopausal women. ARTHRITIS RHEUM. 2013; 65:519-528. [PubMed: 23124535]

Staud R, Bovee CE, Robinson ME, Price DD. Cutaneous C-fiber pain abnormalities of fibromyalgia patients are specifically related to temporal summation. Pain. 2008; 139:315-323. [PubMed: 18538477]

Staud R, Cannon RC, Mauderli AP, Robinson ME, Price DD, Vierck CJ. Temporal summation of pain from mechanical stimulation of muscle tissue in normal controls and subjects with fibromyalgia syndrome. Pain. 2003; 102:87-95. [PubMed: 12620600]

Staud R, Vierck CJ, Robinson ME, Price DD. Effects of the N-methyl-D-aspartate receptor antagonist dextromethorphan on temporal summation of pain are similar in fibromyalgia patients and normal control subjects. J Pain. 2005; 6:323-332. [PubMed: 15890634]

Staud R, Weyl EE, Bartley E, Price DD, Robinson ME. Analgesic and anti-hyperalgesic effects of muscle injections with lidocaine or saline in patients with fibromyalgia syndrome. Eur J Pain. 2014; 18:803-812. [PubMed: 24193993]

Sturgill J, McGee E, Menzies V. Unique cytokine signature in the plasma of patients with fibromyalgia. Journal of immunology research. 2014; 2014:938576. [PubMed: 24741634]

Suarez-Roca H, Leal L, Silva JA, Pinerua-Shuhaibar L, Quintero L. Reduced GABA neurotransmission underlies hyperalgesia induced by repeated forced swimming stress. Behav Brain Res. 2008; 189:159-169. [PubMed: 18255166]

Suarez-Roca H, Silva JA, Arcaya JL, Quintero L, Maixner W, Pinerua-Shuhaibar L. Role of mu-opioid and NMDA receptors in the development and maintenance of repeated swim stress-induced thermal hyperalgesia. Behavioural brain research. 2006; 167:205-211. [PubMed: 16214233]

Svensson P, Cairns BE, Wang K, Arendt-Nielsen L. Injection of nerve growth factor into human masseter muscle evokes long-lasting mechanical allodynia and hyperalgesia. Pain. 2003; 104:241-247. [PubMed: 12855334]

Taguchi T, Katanosaka K, Yasui M, Hayashi K, Yamashita M, Wakatsuki K, Kiyama H, Yamanaka A, Mizumura K. Peripheral and spinal mechanisms of nociception in a rat reserpine-induced pain model. Pain. 2015; 156:415-427. [PubMed: 25599239]

Tchivileva IE, Lim PF, Smith SB, Slade GD, Diatchenko L, McLean SA, Maixner W. Effect of catechol-O-methyltransferase polymorphism on response to propranolol therapy in chronic musculoskeletal pain: a randomized, double-blind, placebo-controlled, crossover pilot study. Pharmacogenetics and genomics. 2010; 20:239-248. [PubMed: 20216107]

Tillu DV, Gebhart GF, Sluka KA. Descending facilitatory pathways from the RVM initiate and maintain bilateral hyperalgesia after muscle insult. Pain. 2008; 136:331-339. [PubMed: 17764841]

Tracey I. "Seeing" how our drugs work brings translational added value. Anesthesiology. 2013; 119:1247-1248. [PubMed: 24343284]

Uceyler N, Hauser W, Sommer C. Systematic review with meta-analysis: cytokines in fibromyalgia syndrome. BMC Musculoskelet Disord. 2011; 12:245. [PubMed: 22034969]

Uceyler N, Zeller D, Kahn AK, Kewenig S, Kittel-Schneider S, Schmid A, Casanova-Molla J, Reiners K, Sommer C. Small fibre pathology in patients with fibromyalgia syndrome. Brain. 2013; 136:1857-1867. [PubMed: 23474848]

Vestergaard-Poulsen P, Thomsen C, Norregaard J, Bulow P, Sinkjaer T, Henriksen O. 31P NMR spectroscopy and electromyography during exercise and recovery in patients with fibromyalgia. Journal of Rheumatology. 1995; 22:1544-1551. [PubMed: 7473481] 
Wager TD, Atlas LY, Lindquist MA, Roy M, Woo CW, Kross E. An fMRI-based neurologic signature of physical pain. N Engl J Med. 2013; 368:1388-1397. [PubMed: 23574118]

Walder RY, Gautam M, Wilson SP, Benson CJ, Sluka KA. Selective Targeting of ASIC3 using miRNAs inhibits primary and secondary hyperalgesia following muscle inflammation. Pain. 2011; 152:2348-2356. [PubMed: 21843914]

Wilder-Smith CH, Robert-Yap J. Abnormal endogenous pain modulation and somatic and visceral hypersensitivity in female patients with irritable bowel syndrome. World J Gastroenterol. 2007; 13:3699-3704. [PubMed: 17659729]

Williams DA, Brown SC, Clauw DJ, Gendreau RM. Self-reported symptoms before and after September 11 in patients with fibromyalgia. JAMA. 2003; 289:1637-1638. [PubMed: 12672730]

Wolfe F. The relation between tender points and fibromyalgia symptom variables: evidence that fibromyalgia is not a discrete disorder in the clinic. Annals of the Rheumatic Diseases. 1997; 56:268-271. [PubMed: 9166001]

Wolfe F, Ross K, Anderson J, Russell IJ. Aspects of fibromyalgia in the general population: Sex, pain threshold, and fibromyalgia symptoms. Journal of Rheumatology. 1995; 22:151-156. [PubMed: 7699662]

Wolfe F, Smythe HA, Yunus MB, Bennett RM, Bombardier C, Goldenberg DL, Tugwell P, Campbell SM, Abeles M, Clark P. The American College of Rheumatology 1990 Criteria for the Classification of Fibromyalgia. Report of the Multicenter Criteria Committee. Arthritis \& Rheumatism. 1990; 33:160-172. [PubMed: 2306288]

Wortmann RL. Searching for the cause of fibromyalgia: Is there a defect in energy metabolism? [editorial; comment]. Arthritis \& Rheumatism. 1994; 37:790-793. [PubMed: 8003049]

$\mathrm{Wu} \mathrm{C}$, Erickson MA, Xu J, Wild KD, Brennan TJ. Expression profile of nerve growth factor after muscle incision in the rat. Anesthesiology. 2009; 110:140-149. [PubMed: 19104181]

Yaksh TL. Pharmacology of spinal adrenergic systems which modulate spinal nociceptive processing. Pharmacol Biochem Behav. 1985; 22:845-858. [PubMed: 2861606]

Yarnitsky D. Conditioned pain modulation (the diffuse noxious inhibitory control-like effect): its relevance for acute and chronic pain states. Curr Opin Anaesthesiol. 2010; 23:611-615. [PubMed: 20543676]

Yarnitsky D, Granot M, Nahman-Averbuch H, Khamaisi M, Granovsky Y. Conditioned pain modulation predicts duloxetine efficacy in painful diabetic neuropathy. Pain. 2012; 153:11931198. [PubMed: 22480803]

Yokoyama T, Audette KM, Sluka KA. Pregabalin reduces muscle and cutaneous hyperalgesia in two models of chronic muscle pain in rats. J Pain. 2007a; 8:422-429. [PubMed: 17293165]

Yokoyama T, Lisi TL, Moore SA, Sluka KA. Muscle Fatigue Increases the Probability of Developing Hyperalgesia in Mice. J Pain. 2007b; 8:692-699. [PubMed: 17627895]

Younger J, Mackey S. Fibromyalgia symptoms are reduced by low-dose naltrexone: a pilot study. Pain Med. 2009; 10:663-672. [PubMed: 19453963]

Yunus M, Masi AT, Calabro JJ, Miller KA, Feigenbaum SL. Primary fibromyalgia (fibrositis): Clinical study of 50 patients with matched normal controls. Seminars in Arthritis and Rheumatism. 1981; 11:151-171. [PubMed: 6944796]

Yunus M, Masi AT, Calabro JJ, Shah IK. Primary fibromyalgia. American Family Physician. 1982; 25:115-121. [PubMed: 6951404]

Yunus MB. Editorial review: an update on central sensitivity syndromes and the issues of nosology and psychobiology. Curr Rheumatol Rev. 2015; 11:70-85. [PubMed: 26138918] 


\section{Highlights}

Fibromyalgia is associated with altered processing in the CNS with enhanced excitability and decreased inhibition

- $\quad$ Animal models mimicking fibromyalgia have discovered a changes in the CNS from the spinal cord to the cortex

- $\quad$ Evidence that supports altered CNS processing in human subjects, and the translational data in animal models on mechanisms 


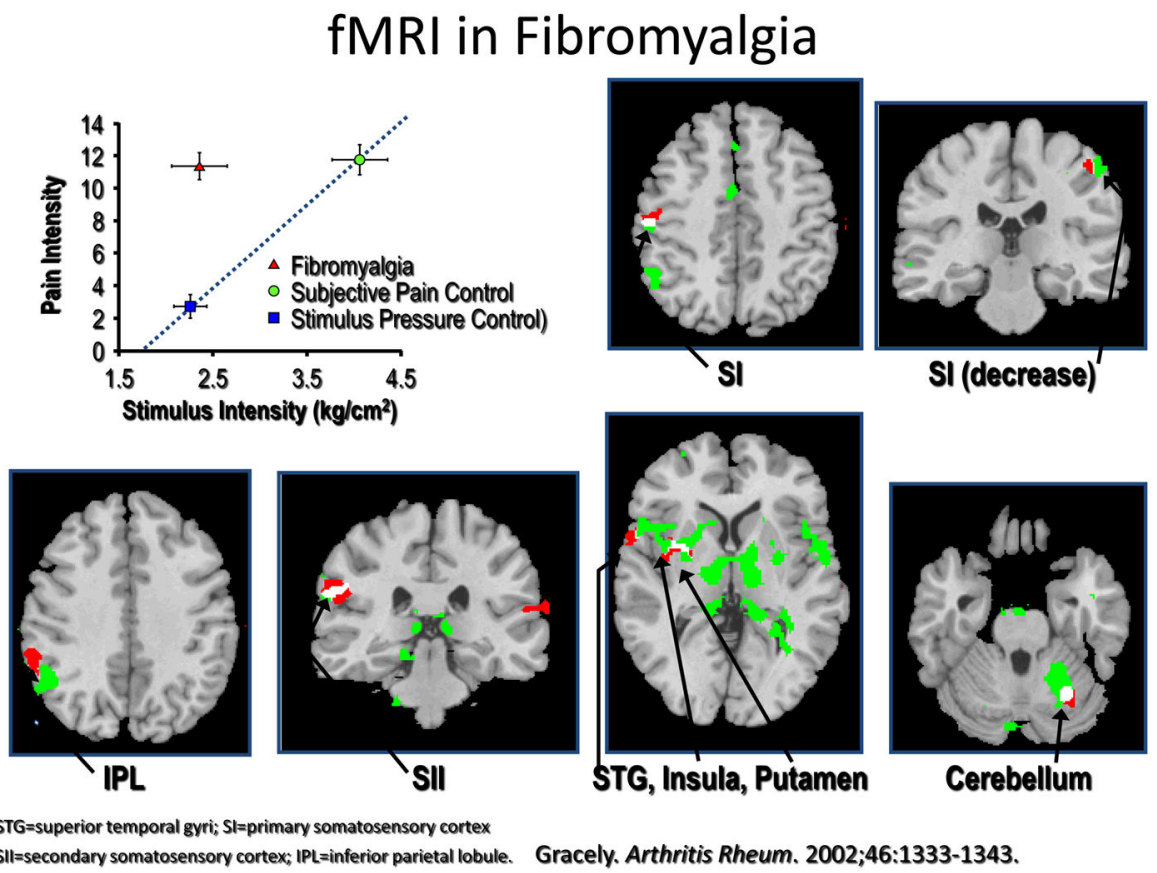

Figure 1.

This is the first fMRI study in fibromyalgia. Individuals with fibromyalgia (in red triangle) were given a low intensity stimulus (shown in top left panel) and this led to moderate pain (a 0-20 Gracely scale was used to rate pain intensity). Their fMRI BOLD responses were compared to controls given approximately the same intensity stimulus (blue box) or a higher intensity stimulus that was necessary to cause the same amount of pain (green circle). There was no significant neuronal activation from this low intensity stimulus in the controls, but there was in fibromyalgia patients, and these areas of neuronal activation overlapped significantly with the brain activation pattern of the controls given nearly twice as much pressure, which was what was needed to cause comparable amounts of pain. 

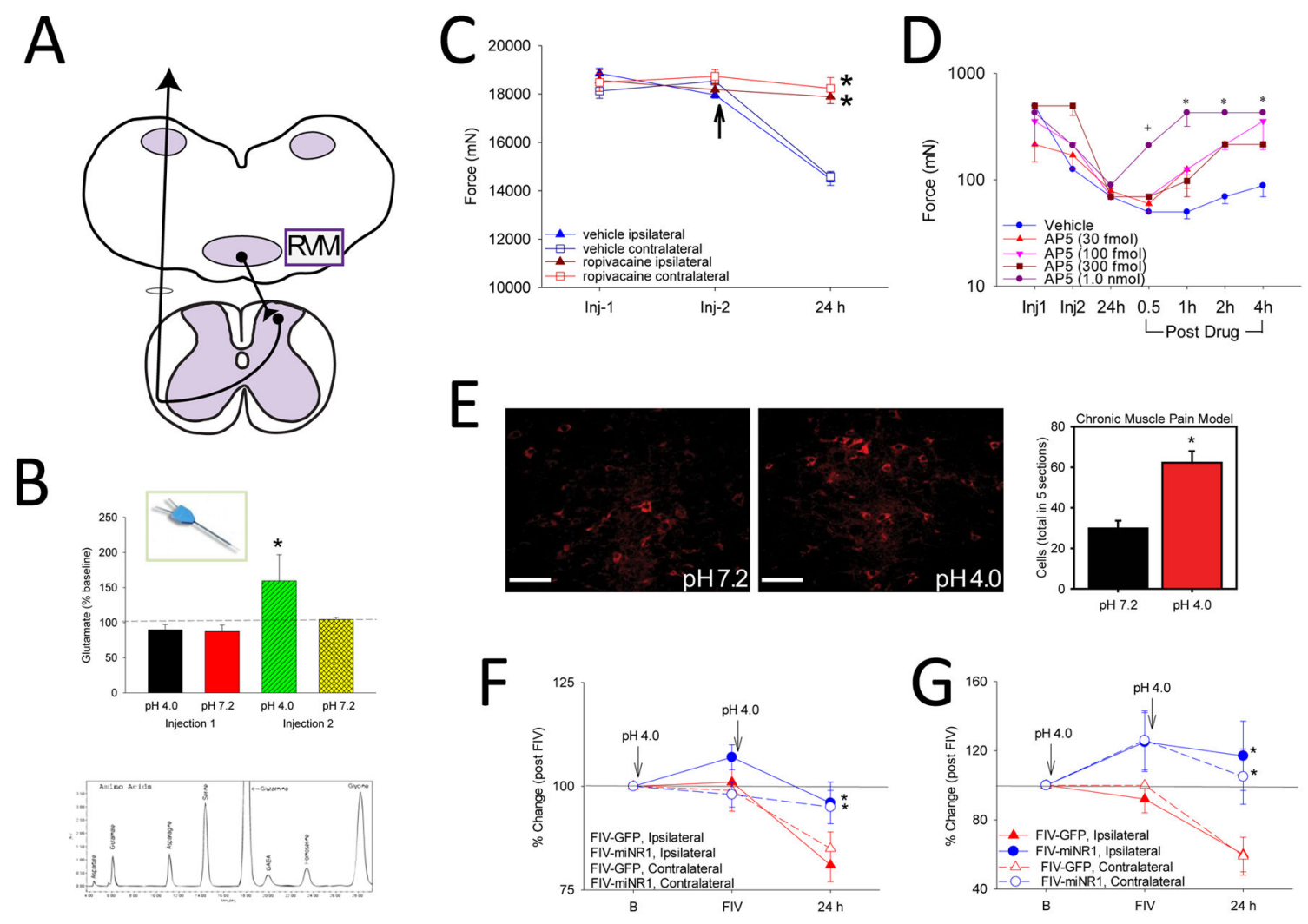

Figure 2.

Central mechanisms involved in the non-inflammatory muscle pain model induced by repeated injections of $\mathrm{pH} 4.0$ saline into the gastrocnemius muscle. A. The rostral ventromedial medulla (RVM) was examined since it sends projections to the spinal cord to facilitate nociception. B. Glutamate release in response to the first and second injection of acidic saline was examined by microdialysis of the RVM. The graph shows an increase in glutamate in response to the second injection of $\mathrm{pH} 4$.0, but not the first. HPLC trace shows amino acids measured in a sample microdialysis sample. Reproduced from (Radhakrishnan and Sluka, 2009). C. Local anesthetic microinjected into the RVM prior to the second injection (arrow) prevents the development of muscle hyperalgesia to repeated acid injection 24 hours later. Reproduced from (Tillu et al., 2008). D. Microinjection of the NMDA receptor antagonist of AP5, dose dependently reverses the mechanical hyperalgesia of the paw induced by repeated acid injection. Reproduced from (da Silva et al., 2010a). E. Repeated injections of acidic saline increase the phosphorylation of the NDMA receptor, NR1 subunit (p-NR1). Images show the staining for pNR1 in the RVM in animals injected with $\mathrm{pH} 7.2$ and those injected with $\mathrm{pH}$ 4.0. The graph shows a significant increase in the number of positively labeled p-NR1 cells in the RVM. Reproduced from (Sluka et al., 2013). F, G. Downregulation of the NR1 subunit, using an FIV vector expressing an miRNA to NR1, prevents the development of paw (F) and muscle (G) hyperalgesia induced by repeated acid injection. Reproduced from (da Silva et al., 2010b). 


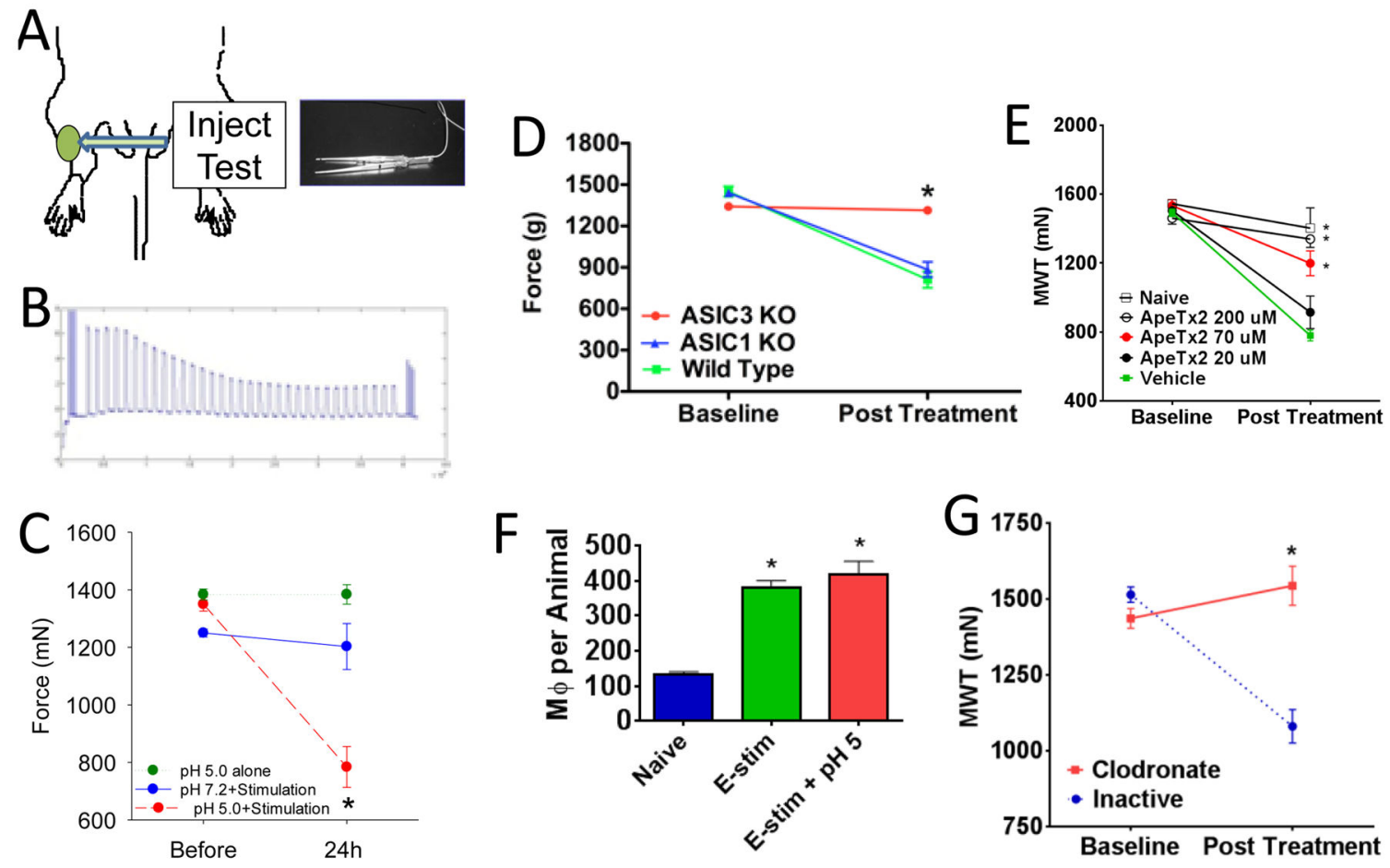

Figure 3.

The fatigue-induced model and the role of local manipulation of ASICs and macrophages.

A. The model is induced by repeated injections of $\mathrm{pH} 5.0$ saline in combination with electrically induced fatigue of the gastrocnemius muscle. Muscle hyperalgesia is assessed by examining the withdrawal threshold to force applied by a pair of tweezers. B. Example of the force output of the muscle during the 6 minute fatiguing task. There is approximately a $50 \%$ decrease in force representing muscle fatigue. C. Muscle withdrawal thresholds after pH 5.0 injections with the fatigue stimulus show a significant decrease (red) when compared to thresholds before, or to thresholds from those that received pH 5.0 alone (green) or fatigue alone (blue). D. There is no decrease in withdrawal thresholds in the fatigue-induced hyperalgesia model in ASIC3 knockout mice (red) when compared to ASIC1 knockout mice (blue) or wild-type controls (green). E. Blockade of ASIC3 results in a dose-dependent blockade of the hyperalgesia induced in the fatigue-induced pain model. F. The fatigue stimulation increases the number of macrophages in muscle when compared to naïve animals that do not receive the fatigue stimulation. G. Removal of macrophages with clodronate liposomes locally in the muscle prevents the hyperalgesia in the fatigue-induced pain model (red) when compared to control liposomes (blue). Reproduced from (Gregory et al., 2013, Gregory et al., 2015b). 